\title{
PARAGONIMUS Y PARAGONIMIASIS EN EL NORTE PERUANO. Proceso del desarrollo de Paragonimus peruvianus Miyazaki, Ibañez y Miranda, 1969 en Felis cati L. gato doméstico infectado experimental- mente.

\author{
Nicanor Ibáñez H., Hernán Miranda C., Eduardo Fernández V. y César Cuba \\ Departamento de Microbiología y Parasitología, \\ Universidad Nacional de Trujilio, Trujillo, Perú.
}

\section{S U M A R IO}

Se ha estudiado el proceso del desarrollo de Paragonimus peruvionus Miyozaki, lbáñez y Miranda, 1969 en el gato doméstico, Felis cati $L$. infectodo experimentalmente mediante la administración oral de metacercorios del porásito extraidas de ejemplores de Pseudothelphusa chilensis Milne Edwards, 1843 procedentes de óreos endémicas.

\section{S U M M A R Y}

The process of the development of Paragonimus peruvianus Miyazaki, Ibánez y Miranda, 1969 in domestic cat Felis cati L. experimentaly infected by means of orally given metacercarias extracted from specimens of Pseudothelphusa chilensis Milne Edwards, 1843 from endemic oreas, has been studied.

\section{INTRODUCCION}

La paragonimiasis fue diagnosticada por primera vez en un peruano nacido $y$ residente en el país por Barton (1910). Con posterioridad, y a lo largo de 50 años, se describieron casos esporádicos, siendo las áreas de procedencia de los pacientes, localidades diversas de los departamentos de Lima y La Libertad. Arce (1915), Corvetto (1921), Cuba (1970). En años recientes se demostró que la enfermedad revestía caracteres de endemia en algunos distritos del departamento de Cajamarca, Morales (1963), Miranda y cols. (1967), Grados y cols. (1967), Cuba (1974). Durante mucho tiempo se pensó que el agente etiológico de la paragonimiasis en el Perú era P. westermani (Kerbert, 1878) Braun, 1899 especie de gran importancia en zonas endémicas de Ásia, Yokogawa (1965) de donde se suponía que el parásito fue importado a través del canal de las migraciones, cuyo destino fueron los valles costeños. Ammel (1934), Arce (1914), Barton (1910), Grados y cols. (1967).

El hallazgo de formas adultas del parásito en un gato procedente de La Asunción (Provincia de Cajamarca, departamento de Cajamarca) y cuyos dueños padecian de paragonimiasis, fue un hecho cuya trascendencia no cabe ya discu- tir, porque fue la evidencia formal que, por primera vez, permitió asegurar la existencia en el Perú, de un parásito del género Paragonimus distinto de $\mathbf{P}$. westermani y al que, por sus características morfológicas, se consideró como una probable especie nueva; Ibáñez y col. (1967), presunción que fue confirmada por Miyazaki y cols (1969) y describiéndose al nuevo trematodo como Paragonimus peruvianus.

Al tratarse de una especie diferente, que posteriormente se encontró extendida a diversas localidades del departamento de Cajamarca, y que, según informes recientes, se halla también en Panamá (Miyazaki, 1972) y, probablemente, en Ecuador (Yokogawa, 1971) y Costa Rica (Miyazaki, comunicación personal), se consideró necesario realizar estudios de diverso orden a fin de conocer, con detenimiento, sus características biológicas. Es asi que, entre los objetivos de este trabajo, estón los de investigar la progresión del desarrollo del parásito desde la metacercaria; conocer la etapa de madurez sexual, estudiar los aspectos morfológicos de los órganos internos, en particular, los del ovario y establecer el índice de recuperación de las formas evolutivas empleando al gato doméstico como ani- 
mal de experimentación y realizar observaciones comparativas entre las formas intrapulmonares y extrapulmonares.

La hipótesis es que, tratándose de una especie nueva, podrían registrarse algunos aspectos biológicos diferentes a los conocidos para otras especies.

\section{MATERIAL Y METODOS}

Las metacercarias de Paragonimus, empleadas en las experiencias, fueron obtenidas del hepatopáncreas de especímenes del crustáceo de agua dulce Pseudothelphusa chilensis Milne Edwards, 1843 recolectados de acequias de zonas endémicas.

El estudio de las metacercarias se hizo en un centenar de formas vivas y en 20 montajes, coloreados con carmín acético. En el primer caso, para precisar la capacidad de supervivencia, características de su movilidad y otros aspectos que no se podría captar en los montajes. Formas recién extraídas fueron administradas, por vía oral, a 37 gatos con edades comprendidas entre 3 y 6 meses, mediante un gotero controlado por estereomicroscopio. Los gatos procedian, en su integridad, de áreas urbanas de la ciudad de Trujillo, $y$, en ningún caso, hubo evidencias de probable infección anterior por Paragonimus.

Las necropsias se realizaron cada quince días, hasta completar los 6 meses; las necropsias restantes se llevaron a cabo a los siete, ocho, diez, doce, catorce y dieciocho meses. En un grupo complementario, se realizaron necropsias a los $35,37,39$ y 41 días.

El número de metacercarias por gato varió entre 10 y 20 y, según fue progresando el trabajo, el número se estabilizó en 20 metacercarias por gato.

El número total de gatos inoculados fue de 37 , con un total de 760 metacercarias.

La anestesia utilizada fue Penthotal, inyectadas por vía intraabdominal.

Durante la disección y antes de abrir las vísceras, se tomó muy especial cuidado en la búsqueda de formas extrapulmo- nares, las que no siempre son fáciles de distinguir. Una vez completa la inspección de cavidades abdominal y toráxica, y con especial atención en mediastino, se procedió a examinar por fuera los pulmones, anotóndose los cambios macroscópicos. También se examinó el encéfalo.

Finalmente se abrió los seudoquistes con precaución, obteniéndose los parásitos por ligera presión.

Los especímenes fueron colocados en suero fisiológico y luego fijados en formol acético, posteriormente se hizo la coloración y montaje.

Las mediciones se hicieron una vez realizados los montajes, mediante un filar micrométrico y los resultados, que se acompañan en tablas, están expresadas en milimetros y micras.

Aparte de la documentación fotográfica, se practicaron dibujos en la cámara clara, para objetivar, con mayor nitidez, algunas formas representativas.

La tabla № 2 está expresada sólo en milímetros y traduce las dimensiones externas. Para su elaboración se tomaron, al azar, cuatro formas de cada edad. Para las micrométricas se escogieron dos formas, por edad, entre las que representaban estructuras internas más nítidas, las mismas que se emplearon para las fotografías.

\section{RESULTADOS}

Los resultados serán expuestos en cuatro partes:

A) Resultados generales.

B) Observaciones adicionales de la Metacercaria.

C) Descripción de las formas Intrapulmonares.

D) Descripción de las formas Extrapulmonares.

\section{A.-Resultados Generales.}

Los gatos inoculados alcanzaron un total de 37. El número de metacercarias por gato y el número de formas evolutivas recuperadas están expresadas en la Tabla No 1, en la que es posible apreciar que las formas extrapulmonares se en- 
cuentran con carácter predominante hasta los 45 días. A partir de este período, tales formas, fueron vistas sólo por excepción.

Se ha comprobado que la progresión del desarrollo es ordenada en las formas intrapulmonares, a diferencia de lo que ocurre en las extrapulmonares, que tienen una evolución irregular. La Tabla $N^{\circ}$ 2 , ilustra gráficamente la progresión del desarrollo en ambos casos. Esta Tabla ha sido preparada en base a mediciones milimétricas.

Las dimensiones externas de los parásitos en las diversas edades, así como las medidas de sus órganos internos, se presentan en las Tablas Nos. 4 - 4A - 4B y $4 C$.

Los aspectos relativos a la anatomía patológica, corresponden a otro trabajo. Sin embargo, queremos reseñar que, en los primeros 45 días, fue posible observar orificios en la pared pulmonar por los que discurrian los parásitos. Desde los 30 días, se pudo objetivar zonas hemorrágicas en la superficie pulmonar de 0.2 a $0.4 \mathrm{~cm}$. de diámetro. Las lesiones de tipo rojo, con relieve en la superficie, y que, dentro, correspondieron a seudoquistes y fueron visibles, con nitidez, desde los 45 días.

Los diámetros de estas formas iniciales alcanzaron de $0.5 \mathrm{~cm}$. a $1.5 \mathrm{~cm}$. La ubicación predominante de estos seudoquistes fue a nivel de los lóbulos medio $y$ posterior.

Abiertos los seudoquistes, se pudo apreciar de 1 a 5 parásitos por cavidad, predominando los pares, habiéndose Ilegado a encontrar, en un solo quiste, nueve ejemplares.

Si bien la periodicidad fijada para los exámenes fue quincenal, tuvimos oportunidad de necropsiar, incidentalmente, un gato que, 5 días antes, había sido inoculado con 13 metacercarias. El examen reveló la presencia de 5 formas evolutivas en cavidad abdominal; una de ellas tras de peritoneo parietal y las restantes, en el borde libre del hígado. El tamaño de estas formas alcanzaba el doble del que corresponde a las metacercarias y presentaban los ciegos intestinales repletos de sangre. (Fig. 2).
En resumen, el porcentaje total de formas evolutivas recuperadas fue de 380 intrapulmonares y 48 extrapulmonares, con un total de 428 , lo que representa un porcentaje de recuperación de 55.31 por ciento.

Los especímenes que han sido motivo del presente estudio, están debidamente registrados en la Colección Helmitológica del Departamento de Microbiología y $\mathrm{Pa}$ rasitología de la Universidad Nacional de Trujillo, y ocupan los numerales que van del 194 al 375 , con sus letras correspondientes.

\section{B.-Observaciones adicionales de la Metacercaria.}

Los especímenes fueron extraídos, previa paralización del cangrejo, mediante destrucción de plexos nerviosos, con estilete.

El indice de infección natural, así como otros aspectos relativos al segundo huésped, son temas de otro trabajo.

Las metacercarias mostraban gran movilidad, tanto al ser extraidas de crustáceos vivos, como de ejemplares muertos. Se hallaron formas muy móviles aún en cangrejos muertos 4 días antes y en estado de putrefacción, comprobándose, definitivamente, que en ninguna circunstancia pudo observarse envoltura quística, lo que explica la activa movilidad del parásito, que se alargaba y retraía con facilidad, al par que las ventosas se abrian y cerraban con energía.

Los ciegos intestinales, de trayecto sinuoso, presentan un color amarillento.

El tubo excretor se extiende desde la bifurcación de los intestinos hasta el extremo posterior $y$ aparece con un matiz oscuro. Es notable ver, en la mayoría de las larvas, pequeños gránulos de color rosado intenso, distribuídos en diversos sectores del cuerpo.

Las dimensiones registradas son las siguientes:

Largo: $1.325 \mathrm{~mm}$.

Ancho: $0.652 \mathrm{~mm}$.

Ventosa oral: $0.106 \mathrm{~mm}$ de largo y 0.131 $\mathrm{mm}$. de ancho. 
Acetóbulo: $0.250 \mathrm{~mm}$. de largo y 0.233 $\mathrm{mm}$. de ancho.

Relación V.O. y V.V.: 1:1.76 y 1:2.04.

Distancia entre el centro de la V.O y el acetábulo: $0.699 \mathrm{~mm}$., de promedio.

Faringe: $0.095 \mathrm{~mm}$. de largo y 0.069 $\mathrm{mm}$. de ancho.

Esófago: $0.052 \mathrm{~mm}$. de largo y 0.042 $\mathrm{mm}$. de ancho.

Area que ocupan las células masculinas: $0.031 \mathrm{~mm}$. de largo por $0.021 \mathrm{~mm}$. de ancho.

Area que ocupan las células femeninas: $0.036 \mathrm{~mm}$. de largo por $0.021 \mathrm{~mm}$. de ancho. (Tabla $N^{\circ} 3$ ).

Si bien no se ha realizado un determinado estudio de las características biológicas de la metacercaria, se puede ofrecer las siguientes informaciones:

La movilidad se mantuvo, por encima de los 5 días, en Suero Fisiológico. Por otro lado, fue posible recuperar el $100 \%$ de parásitos en un gato que recibió 5 metacercarias, extraidas 30 horas atrós. En otro gato se obtuvo 9 formas evolutivas inoculadas 12 metacercarias extraídas con una anticipación de 20 horas.

\section{C._Formas Intrapulmonares.}

a) Las formas de quince dias de edad (Fig. 3) alcanzaron en promedio de 2.518 $\mathrm{mm}$. de largo por $1.303 \mathrm{~mm}$. de ancho. Tabla No 4 .

Los órganos internos presentaron las siguientes caracteristicas:

Glándulas vitelinas: ausentes.

Testículos: esbozos consistentes en pequeños grupos de células.

Ovario: representado por un pequeño esbozo post-acetabular.

Utero: esbozo formado por un grupo de células.

Acetábulo: ecuatorial. b) Formas de $\mathbf{3 0}$ días (Fig. 4) Alcanzaron un promedio de $4.498 \mathrm{~mm}$. de largo y $2.210 \mathrm{~mm}$. de ancho.

Glándulas vitelinas: ausentes.

Testículos: presencia de lobulaciones y conducto deferente.

Ovarios: toma el aspecto de cáliz de una flor alargada con ramificación incipiente.

Utero: se delinea como un fino conducto carente de huevos.

Acetábulo: ecuatorial.

c) Formas de 37 días (Fig. 5) Alcanzaron una longitud que varía entre 5.720 $\mathrm{mm}$. y $5.604 \mathrm{~mm}$. y un ancho que va de $2.860 \mathrm{~mm}$. a $3.380 \mathrm{~mm}$.

Glándulas vitelinas: uniformemente repartidas en el área cecal; pobremente poblados. Viteloductos presentes.

Testículos: con lobulaciones gruesas y manifiestas.

Ovario: representado por un solo cuerpo del que se desprenden escasas lobulaciones; desarrollo incompleto.

Glándulas de Mehlis: presente; poco desarrollada.

Utero: con asas muy escasas, ubicado en área intracecal. Presencia, en un ejemplar, de huevos operculados de apariencia normal.

Testículos: en crecimiento, con escasas lobulaciones.

Acetábulo: precuatorial.

Los úteros de nueve formas, de la misma edad, carecían de huevos.

A los 39 días se encontró huevos en útero de uno de diez ejemplares. $Y$ a los 41 días, en uno de siete.

Los demás órganos no mostraron cambios en relación con la forma de 37 dias, salvo una ramificación mós notoria de los ovarios. 
cuentran con carácter predominante hasta los 45 dias. A partir de este período, tales formas, fueron vistas sólo por excepción.

Se ha comprobado que la progresión del desarrollo es ordenada en las formas intrapulmonares, a diferencia de lo que ocurre en las extrapulmonares, que tienen una evolución irregular. La Tabla No 2 , ilustra gráficamente la progresión del desarrollo en ambos casos. Esta Tabla ha sido preparada en base a mediciones milimétricas.

Las dimensiones externas de los parásitos en las diversas edades, así como las medidas de sus órganos internos, se presentan en las Tablas Nos. 4 - 4A - 4B y 4 C.

Los aspectos relativos a la anatomía patológica, corresponden a otro trabajo. Sin embargo, queremos reseñar que, en los primeros 45 días, fue posible observar orificios en la pared pulmonar por los que discurrían los parásitos. Desde los 30 días, se pudo objetivar zonas hemorrágicas en la superficie pulmonar de 0.2 a $0.4 \mathrm{~cm}$. de diámetro. Las lesiones de tipo rojo, con relieve en la superficie, y que, dentro, correspondieron a seudoquistes y fueron visibles, con nitidez, desde los 45 dias.

Los diómetros de estas formas iniciales alcanzaron de $0.5 \mathrm{~cm}$. a $1.5 \mathrm{~cm}$. La ubicación predominante de estos seudoquistes fue a nivel de los lóbulos medio $y$ posterior.

Abiertos los seudoquistes, se pudo apreciar de 1 a 5 parásitos por cavidad, predominando los pares, habiéndose llegado a encontrar, en un solo quiste, nueve ejemplares.

Si bien la periodicidad fijada para los exámenes fue quincenal, tuvimos oportunidad de necropsiar, incidentalmente, un gato que, 5 días antes, habia sido inoculado con 13 metacercarias. El examen reveló la presencia de 5 formas evolutivas en cavidad abdominal; una de ellas tras de peritoneo parietal y las restantes, en el borde libre del higado. El tamaño de estas formas alcanzaba el doble del que corresponde a las metacercarias y presentaban los ciegos intestinales repletos de sangre. (Fig. 2).
En resumen, el porcentaje total de formas evolutivas recuperadas fue de 380 intrapulmonares y 48 extrapulmonares, con un total de 428 , lo que representa un porcentaje de recuperación de 55.31 por ciento.

Los especimenes que han sido motivo del presente estudio, están debidamente registrados en la Colección Helmitológica del Departamento de Microbiología y Parasitología de la Universidad Nacional de Trujillo, y ocupan los numerales que van del 194 al 375 , con sus letras correspondientes.

\section{B.-Observaciones adicionales de la Metacercaria.}

Los especímenes fueron extraídos, previa paralización del cangrejo, mediante destrucción de plexos nerviosos, con estilete.

El indice de infección natural, asi como otros aspectos relativos al segundo huésped, son temas de otro trabajo.

Las metacercarias mostraban gran movilidad, tanto al ser extraídas de crustáceos vivos, como de ejemplares muertos. Se hallaron formas muy móviles aún en cangrejos muertos 4 días antes y en estado de putrefacción, comprobándose, definitivamente, que en ninguna circunstancia pudo observarse envoltura quística, lo que explica la activa movilidad del parósito, que se alargaba y retraía con facilidad, al par que las ventosas se abrían y cerraban con energía.

Los ciegos intestinales, de trayecto sinuoso, presentan un color amarillento.

El tubo excretor se extiende desde la bifurcación de los intestinos hasta el extremo posterior $y$ aparece con un matiz oscuro. Es notable ver, en la mayoría de las larvas, pequeños gránulos de color rosado intenso, distribuídos en diversos sectores del cuerpo.

Las dimensiones registradas son las siguientes:

Largo: $1.325 \mathrm{~mm}$.

Ancho: $0.652 \mathrm{~mm}$.

Ventosa oral: $0.106 \mathrm{~mm}$ de largo y 0.131 $\mathrm{mm}$. de ancho. 
Acetábulo: $0.250 \mathrm{~mm}$. de largo y 0.233 $\mathrm{mm}$. de ancho.

Relación V.O. y V.V.: 1:1.76 y 1:2.04.

Distancia entre el centro de la V.O y el acetábulo: $0.699 \mathrm{~mm}$., de promedio.

Faringe: $0.095 \mathrm{~mm}$. de largo y 0.069 $\mathrm{mm}$. de ancho.

Esófago: $0.052 \mathrm{~mm}$. de largo y 0.042 $\mathrm{mm}$. de ancho.

Area que ocupan las células masculinas: $0.031 \mathrm{~mm}$. de largo por $0.021 \mathrm{~mm}$. de ancho.

Area que ocupan las células femeninas: $0.036 \mathrm{~mm}$. de largo por $0.021 \mathrm{~mm}$. de ancho. (Tabla No 3 ).

Si bien no se ha realizado un determinado estudio de las características biológicas de la metacercaria, se puede ofrecer las siguientes informaciones:

La movilidad se mantuvo, por encima de los 5 días, en Suero Fisiológico. Por otro lado, fue posible recuperar el 100\% de parásitos en un gato que recibió 5 metacercarias, extraidas 30 horas atrós. En otro gato se obtuvo 9 formas evolutivas inoculadas 12 metacercarias extraidas con una anticipación de 20 horas.

\section{C.-Formas Intrapulmonares.}

a) Las formas de quince dias de edad (Fig. 3) alcanzaron en promedio de 2.518 $\mathrm{mm}$. de largo por $1.303 \mathrm{~mm}$. de ancho. Tabla No 4 .

Los órganos internos presentaron las siguientes características:

Glándulas vitelinas: ausentes.

Testículos: esbozos consistentes en pequeños grupos de células.

Ovario: representado por un pequeño esbozo post-acetabular.

Utero: esbozo formado por un grupo de células.

Acetábulo: ecuatorial. b) Formas de 30 días (Fig. 4) Alcanzaron un promedio de $4.498 \mathrm{~mm}$. de largo y $2.210 \mathrm{~mm}$. de ancho.

Glóndulas vitelinas: ausentes.

Testiculos: presencia de lobulaciones $y$ conducto deferente.

Ovarios: toma el aspecto de cáliz de una flor alargada con ramificación incipiente.

Utero: se delinea como un fino conducto carente de huevos.

Acetábulo: ecuatorial.

c) Formas de 37 dias (Fig. 5) Alcanzaron una longitud que varía entre 5.720 $\mathrm{mm}$. y $5.604 \mathrm{~mm}$. y un ancho que va de $2.860 \mathrm{~mm}$. a $3.380 \mathrm{~mm}$.

Glóndulas vitelinas: uniformemente repartidas en el área cecal; pobremente poblados. Viteloductos presentes.

Testículos: con lobulaciones gruesas y manifiestas.

Ovario: representado por un solo cuerpo del que se desprenden escasas lobulaciones; desarrollo incompleto.

Glándulas de Mehlis: presente; poco desarrollada.

Utero: con asas muy escasas, ubicado en área intracecal. Presencia, en un ejemplar, de huevos operculados de apariencia normal.

Testículos: en crecimiento, con escasas lobulaciones.

Acetábulo: precuatorial.

Los úteros de nueve formas, de la misma edad, carecían de huevos.

A los 39 días se encontró huevos en útero de uno de diez ejemplares. $Y$ a los 41 días, en uno de siete.

Los demás órganos no mostraron cambios en relación con la forma de 37 dias, salvo una ramificación más notoria de los ovarios. 
d) Formas de $\mathbf{4 5}$ días (Fig. 6) Longitud mediana de $7.507 \mathrm{~mm}$. y ancho de $3.672 \mathrm{~mm}$.

Glándulas vitelinas: abundantes; se aprecia la presencia de viteloductos. Las glándulas son extracecales e intracecales.

Testículos: desarrollado, siendo el derecho de mayor tamaño; abundantes lobulaciones en ambos lados. Son post-acetabulares. En la mayoría de los ejemplares están a la misma altu ra y muy próximos uno de otro.

Ovario: con 13 a 15 ramificaciones cortas; cuerpo con apariencia del cóliz de una flor que descansa sobre la glándula de Mehlis. El ovario ocupa el campo del testículo derecho $y$, en algunos ejemplares, está en zona del acetábulo.

Glándula de Mehlis: que es visible a partir de esta edad.

Utero: repleto de huevos, los que presentan una longitud de 84 a 86 micras de largo y de 33 a 42 de ancho. EI poro genital esta por delante del acetábulo. El útero presenta asas ascendentes y descendentes en su área respectiva: las que sobrepasan el acetábulo y llegan a relacionarse con las lobulaciones superiores del testículo izquierdo.

Acetábulo: Es precuatorial. La totalidad de diez formas examinadas presentaban abundantes huevos a lo largo de las asas uterinas.

e) Formas de $\mathbf{6 0}$ días (Fig. 7) Longitud promedio: $9.295 \mathrm{~mm}$. Ancho promedio: $4.310 \mathrm{~mm}$.

Glándulas vitelinas: más abundantes que en la etapa anterior. Los viteloductos de mayor calibre.

Testículos: más desarrollados que a los 45 días, tanto en longitud como en diámetro. El testículo izquierdo, algo más pequeño y más bajo que el derecho.

Ovario: con prolongaciones más numerosas que alcanzan, en conjunto, hasta 25 en algunos ejemplares.
Utero: con asas más gruesas, abarca una área mayor que en la etapa precedente. Los huevos, de iguales caracteres a los señalados.

Acetábulo: es precuatorial. El poro genital por delante del acetábulo.

En las formas de $75,90,105,120$, $150,180,210,240,300,360$ y 540 dias se observa un desarrollo ordenado tanto en longitud como en ancho, salvo en los especímenes obtenidos a los 41 y a los 360 dias, que fueron más pequeños que los de 300 dias.

Figs. 8 al 17 y Tabla 2.

Los órganos internos, incrementaron sus dimensiones en forma progresiva. $\mathrm{Pa}$ ra una mayor ilustración se ha elaborado tablas para cada edad en las que se puede encontrar, en detalle, las medidas correspondientes a las dimensiones de los parásitos y de los órganos internos en cada etapa. (Tabla 4).

\section{D.-Descripción de las Formas Extrapulmonares.}

Los hallazgos fondamentales en estas formas, son las siguientes:

Las Glándulas vitelógenas no son visibles hasta los 45 días (Fig. 20). A partir de esta edad, se nota un esbozo de glándulas que, aún a los seis meses, siguen exhibiendo sólo un desarrollo rudimentario. Los viteloductos son visibles solamente en las formas de 180 días y presentan un calibre delgado. Esbozos de las glándulas de Mehlis, son observables en las formas de 30 días. No se observa en las formas de $45,60,105$ y 120 días. Se presentó nítida, aunque poco desarrollado, en las formas de 90, 150 y 180 dias (Figs. 26-27).

El útero aparece tenuemente esbozado en las formas de 30 días (Fig. 18) y toma el aspecto de pequeñas manchas. El esbozo se acentúa, en forma leve, en los períodos sucesivos, sin lograr conformar asas uterinas, las que recién aparecen a los 180 días. Las asas son cortas, delgadas y contienen sólo escasos huevos, cuya forma y estructura difieren de los correspondientes huevos de úteros de formas intrapulmonares (Figs. 25-26-27). 
Los contornos del ovario se aprecian con cierta nitidez a partir de los 45 dias. Según avanzan en edad los parásitos, las ramificaciones del ovario se alargan y difieren marcadamente de los ovarios normales tanto en forma como en tamaño (Figs. 21-22-23), alcanzando dimensiones menores y adoptando un aspecto dentrítico que contrasta con el aspecto de los ovarios de las formas intrapulmonares de las mismas edades (Figs. 24 y 26 ).

Los testículos se esbozan desde los 15 dias y adquieren formas más nítidas a los 45 dias. A los 120 días su desarrollo es retardado e incompleto y a los 180 , presenta ramificaciones filiformes y su aspecto general difiere categóricamente de los testículos de especimenes intrapulmonares de edades similares (Figs. 24-26).

Las dimensiones, obviamente, son menores.

Los huevos han sido observados, por excepción, a los 60 días en cantidad exigua. No se encontraron en otras formas hasta los 180 días, edad en la que se observó la presencia de muy escasos huevos, transparentes, redondeados o irregulares, con dimensiones de 69 por 42 micras, que constrastan con las dimensiones de huevos normales que alcanzan 80 micras de longitud por 46 de ancho. La envoltura se aprecia sumamente delgada y el opérculo no fue observable.

Para apreciar con mayor nitidez los aspectos relativos a desarrollo y dimensiones de las formas extrapulmonares, se ha preparado la Tabla No 5.

Es también fácil apreciar algunos aspectos morfológicos en los dibujos a la cámara clara (Figs. 25 y 27 ).

\section{DISCUSION}

Los comentarios se harán siguiendo el esquema de cuatro puntos, adaptado en los capítulos anteriores:

I.- En los resultados generales se observa que, de un total de 760 metacercarias administradas experimentalmente a 37 gatos domésticos, se ha recuperado un total de 428 formas evolutivas; de éstas, 380 fueron intrapulmonares y 48 extrapulmonares. En la Tabla $N^{\circ} 1$ puede apreciarse que las formas extrapulmona- res fueron observadas con mayor frecuencia dentro de los primeros 45 dias. Tales formas se encontraban mayormente en diafragma y mediastino.

En las primeras fases del estudio ha sido llamativo el hallazgo de orificios en la pared pulmonar por los cuales discurrían los parósitos, aparentemente, en busca de su ubicación definitiva.

A partir de los dos meses, las formas extrapulmonares fueron escasas; pero fue posible hallar algunas hasta los 6 meses.

No disponemos de una información que aclare, con plenitud, estos hechos. Lo cierto es que el proceso de formación del pseudoquiste alcanza una mejor configuración, justamente alrededor de los dos meses, tal como se muestra en un estudio histopatológico, motivo de otro trabajo, dentro de este programa; este hecho podría determinar un menor desplazamiento del parásito.

En base a las observaciones referidas queda la interrogante de si las formas extrapulmonares mueren y son destruídas o finalmente logran penetrar al pulmón; esta última posibilidad podría encontrar respaldo en el hecho de que en los estudios histopatológicos se encuentran cavidades perfectamente organizadas $y$ fibrosas junto con otras de edad, evidentemente, menor.

En las experiencias realizadas por Yokogawa y cols. (1960) con metacercarias de P. westermani en perros, y por Yoshida (1970) en roedores, los que fueron inoculados con metacercarias de Paragonimus miyazakii, llama la atención que, en aquellos casos en los que se inoculó animales con una sola metacercaria, el parásito fue extrapulmonar y en ningún caso se observó formación de quiste, a diferencia de lo que ocurrió cuando se inoculó con más de una metacercaria por animal. No sabemos cuál sea el comportamiento de metacercarias de Paragonimus peruvianus inoculados a razón de una por animal. En cuanto al concepto de madurez sexual, surge, para nosotros, el problema de definirlo con propiedad $y$, en principio, hemos creido conveniente usar el término como sinónimo de presencia o aparición de huevos en útero en número apreciable y con caracteres semejantes a los huevos 
de parásitos adultos. La razón para la duda expuesta estó en que la aparición de huevos en útero precede en varios dias su presencia en la cavidad quística $y$, en muchos más, su aparición en heces. Tenemos como ejemplo la observación de Hashigushi, Takey y Miyazaki (1969), quienes han establecido que los huevos de P. miyazakii son visibles en útero a partir de cincuenta días en rata albina; aparecen en la cavidad quística a los cincuentiocho y se encuentra en heces a los sesenticinco días. ¿A cuál de estos hechos llamaremos madurez sexual?. Preferimos considerar como tal, la aparición de huevos en útero, por ser el hecho más precoz y objetivo. Sería, tal vez, pertinente dar una definición convencional al respecto y ésta podría ser "la edad en que, no menos del $50 \%$ de diez ejemplares, presentan huevos en útero". El hallazgo de huevos en cavidad quistica, o en heces, son fenómenos ulteriores y que no podrian tomarse como equivalentes de madurez sexual.

Al comparar los datos registrados, vemos que la edad mínima en que aparecen huevos en útero ha sido registrada por Hashiguchi y cols. (1969) en P. ohirai inoculado en ratas por vía pleural, observóndose los huevos desde los 20 dias; en 14 de 31 a los 25 días; en 42 de 44 , a los 35 días y en 29 de 30 a los 40 días.

La especie P. kellicotti produjo huevos entre 38 y 42 días en gatos. Ishii (1966).

Podría asegurarse que ninguna forma extrapulmonar alcanzó, dentro de los seis meses de observación, su madurez sexual; en cambio, huevos de estas características fueron observados nítidamente y en gran número en los parásitos intrapulmonares desde los cuarenticinco días. (Fig. 6). En los extrapulmonares se encontró, por excepción, uno que otro huevo a los sesenta días y no volvió a verse alguno hasta los seis meses en que se observó escasos huevos atípicos, deformes, translúcidos y con cutícula muy delgada. Estas observaciones señalan, con claridad, que el parásito alcanza madurez sexual sólamente en los seudoquistes. También se ha hecho énfasis en el hecho de que, tal madurez, requiere el apareamiento de dos o más parásitos que ocupan la misma cavidad. Acerca de los expuesto, son pertinentes los siguientes comentarios: a) Las metacercarias de Paragonimus westermani inoculadas, a razón de una por cada perro, por Yokogawa, Yoshimura y Oshima (1960), no forman quiste, como ya se ha anotado, y tampoco lograron madurez sexual. Igual ocurrió en el trabajo de Yokogawa, Yoshimura y Tsuji (1961), lo que permitió, a estos autores, sugerir la posibilidad de que es necesaria la fecundación cruzada para lograr madurez sexual y la formación del quiste parasitario. Por contraste, según Yoshida (1970), no ocurre lo mismo en Paragonimus miyazakii, pues este parásito alcanzó madurez sexual aún tratándose de individuos aislados; es cierto que no lograron formar quiste, pero depositaron huevos en las áreas extrapulmonares que ocupaban.

Los huevos tenían menor vitalidad que los procedentes de formas intrapulmonares. Hashiguchi, Takei y Miyazaki (1969), llegan a iguales conclusiones trabajando con Paragonimus ohirai.

Es de particular interés, hacer un comentario relacionado con la distribución geográfica del Paragonimus peruvianus. Existen, al respecto, informaciones muy valiosas; así, Yokogawa (1971), en un estudio realizado en el Ecuador, obtuvo en áreas endémicas, metacercarias carentes de envoltura quística, idénticas a las Paragonimus peruvianus en dimensiones $y$ aspecto. Por otra parte, Miyazaki (1972), confirmó la existencia de la especie en Panamá y en Costa Rica (Com. personal). En una visita, realizada por uno de los autores (H. M. C.), a San José, hubo ocasión de ver la colección del Dr. Rodrigo Brenes, notándose que, parte de los ejemplares, tenían los caracteres morfológicos de P. peruvianus. Se desprende de lo expuesto que la distribución de esta especie parece ser sumamente extensa. En un trabajo, realizado en el Departamento de Cajamarca, se comprobó que estó presente en todas las áreas estudiadas. Cuba y cols. (1974). La única especie adicional hallada, hasta el momento, en porcentaje mínimo es P. caliensis Little, 1968 cuya presencia había sido ya señalada por otros autores en fecha reciente. (Miyazaki y Grados, 1972).

Finalmente, cabe reiterar que, en el Ecuador, Panamá y Costa Rica, se han encontrado metacercarias sin envoltura quística de dos tipos diferentes. 
11. - Los comentarios relacionados con la metacercaria inciden, principalmente, en la ausencia de envoltura quística (Miyazaki y cols., 1969), a diferencia de los parásitos asiáticos, algunos de los cuales tienen doble membrana, como $\mathbf{P}$. westermani, P. ohirai y P. miyazakii (Miyazaki, 1939; Miyazaki, 1965; Miyazaki, 1972). Otros tienen una sola envoltura, como P. iloksuenensis. P. kellicotti presenta la metacercaria con doble envoltura, en cambio P. caliensis tiene sólo una (Little, 1968). A pesar de lo expuesto, resalta la extraordinaria vitalidad de la metacercaria de $\mathbf{P}$. peruvianus, cuya supervivencia en suero fisiológico es muy larga, llegando hasta los diez días, manteniendo una buena capacidad infectante.

La supervivencia de la metacercaria en los crustáceos muertos fue comprobada por nosotros hasta el término de cuatro días en condiciones ambientales (Temperatura media: $23^{\circ} \mathrm{C}$. En jugo puro de limón mantuvo movilidad hasta por tres horas, lo cual es importante, en razón de que la forma de ingestión de los crustáceos, en áreas endémicas, es, justamente, preparándolos con jugo de limón.

Cabe destacar que no se ha realizado, hasta donde sabemos, un estudio exhaustivo acerca de la vitalidad de la metacercaria.

Citaremos algunos datos sobre metacercarias de otras especies: las de $\mathbf{P}$. westermani, extraídas de cuerpos muertos de Eriocheir japonicus, se mantuvieron vivas de 3 a 5 días, en verano y de 10 a 20 dias, cuando eran refrigeradas entre $4^{\circ} \mathrm{y}$ $5^{\circ} \mathrm{C}$.

Las metacercarias de Paragonimus westermani se mantuvieron vivas en el cuerpo muerto del crustáceo, refrigerado a $2^{\circ}$ y $5^{\circ} \mathrm{C}$., por un periodo de 3 a 4 semanas. También fue posible mantenerlas vivas por cuatro meses, a $5^{\circ} \mathrm{C}$., en una solución del mismo valor osmótico que el del crustáceo. Según Ando y Nakagawa (Cit. por Yokogawa, 1965), a $55^{\circ} \mathrm{C}$ por 20 minutos, murieron todas las metacercarias en el cuerpo del cangrejo; resistieron por más de 24 horas en vinagre, azúcar, sal $y$ "sake-kasu". Si se congelan por cierto tiempo y se calienta lentamente, recuperan su actividad. A $40^{\circ} \mathrm{C}$, todas murieron en $30^{\circ} \mathrm{C}$. La metacercaria fue altamente vulnerable a la desecación. (1965).

III. - De manera impensada y fuera de esquema, al morir un gato, tuvimos ocasión de observar formas a los cinco dias de inoculación. De trece metacercarias inoculadas, se recuperaron cinco formas, una de ellas, tras de peritoneo parietal y las demás en cavidad abdominal libre.

La longitud media era de largo más de dos milímetros (Fig. 2).

Ninguna fue encontrada en cavidad toráxica.

A los quince días, se encontraron formas intratoróxicas y ninguna en el abdomen ni otra localización. De diez metacercarias se recuperaron cuatro formas evolutivas extrapulmonares (Tabla $N^{\circ} 1$ ), en todas las que se observó esbozos de testiculo y ovario y ausencia de vitelógenos (Fig. 3).

A los 30 días (Fig. 4), se observó, con gran nitidez, el contorno de los órganos sexuales persistiendo la ausencia de vitelógenos. En esta edad es que se encontraron parásitos intrapulmonares con formación incipiente de seudoquiste. Es recién a los treintisiete dias que se encontró escasos huevos en uno de los diez ejemplares; fue a esta misma edad que se observó, por primera vez, la glándula de Mehlis. A los trintinueve días se encontró, igualmente, huevos en uno de diez parósitos; a los cuarentiuno, en uno de siete y a los cuarenticinco dias, la totalidad de las formas tenían útero repleto de huevos (Fig. 6). Las lobulaciones del ovario se notaron recién, con claridad, a los cuarenticinco días $y$, en forma incipiente, en edades anteriores.

Miyazaki $(1970,1972)$ al tratar de la sistematización del Género, da especial importancia a la morfología del ovario, a la forma y disposición de las espinas, a la relación entre ventosa oral y ventral, a la morfología de los testículos. A estos datos agrega los caracteres de las metacercarias que presentan una o dos envolturas, 0 ninguna, y la forma y dimensiones de los huevos, agregándose los recursos del "scanning electron microscope" para el estudio de la superficie (Ishii y Miyazaki, 1971). A cada especie corresponde una 
asociación de características morfológicas diversas, de manera que, en casos de semejanza de algún elemento, habrán otros muy definidos que marcan la diferencia.

El ovario es uno de los elementos primordiales considerado aisladamente; este concepto sirvió de base a la descripción de P. ohirai diferenciándolo de P. westermani.

En el presente estudio se aprecia que el número de lobulaciones en $\mathbf{P}$. peruvianus se insinúa precozmente y no presenta cambios radicales hasta la edad máxima estudiada que es de 18 meses; es decir que, una forma de mayor edad, no exhibe necesariamente, mayor número de lobulaciones que una más tierna. Tal aseveración está respaldada tanto por la secuencia fotográfica, que se acompaña, como por los dibujos, a la cómara clara, de catorce ovarios de distinta edad (Fig. 28). A partir de los 60 días, puede decirse que el ovario tiene una configuración que se conserva en edades ulteriores. El incremento se registra en las ramificaciones más pequeñas. El ovario ocupó el lado derecho en 154 ejemplares, y el lado izquierdo en 22 , lo que representa el 87.6 y el $12.4 \%$ de 176 parásitos observados.

Se ha encontrado en $\mathbf{P}$. westermani las siguientes relaciones de ubicación de ovarios: $11-7$; $30-30$; $6-24$ y $50-50$ respectivamente, correspondiendo los primeros números a la posición izquierda.

El tamaño de las formas intrapulmonares siguió una progresión más ordenada, lo que no significa que, en grupos de la misma edad, no se registran formas de distinto tamaño; sin embargo, en promedio, el incremento de las medidas fue regular, salvo dos excepciones notorias a los 360 y a los 420 días. La menor dimensión de las formas de un año podría atribuirse a que el gato recibió $100 \mathrm{me}-$ tacercarias, recuperándose 36 formas que presenta un número mucho mayor que el logrado en otros gatos. No hemos podido explicar el menor desarrollo de los parásitos de 420 días. Para las Tablas Micrométricas $\mathrm{N}^{\circ} 4$ y siguientes, se escogieron los especímenes que presentaban estructuras más nítidas y en número de dos por cada edad. Para la Tabla Milimétrica No 2 , se empleó un promedio de 4 ejemplares por cada edad, escogidos al azar. Las fotografías se tomaron de los especímenes con órganos internos mejor observables. De ello resulta que no hay una exacta superposición entre las medidas presentadas, si bien prevalece la imagen de un desarrollo más ordenado en la Tabla $\mathrm{Mi}$ limétrica, que es más representativa en lo referente a dimensiones externas, por referirse a mayor número de ejemplares, los mismos que fueron elegidos al azar.

Las glándulas vitelógenas de las formas intrapulmonares mostraron gran desarrollo (Fig. 25). El útero mostraba numerosas asas repletas de huevos.

Los testículos merecen, desde el punto de vista morfológico, las mismas consideraciones que el ovario, pues las ramificaciones no sufrieron, después de lograda cierta madurez, cambios sustanciales (Figs. 29 y 30 ).

IV.-Las formas extralpumonares se encontraron, con alguna frecuencia, en los primeros cuarenticinco días y, más raramente, hasta los 6 meses, después de los cuales no se encontró forma algna de este tipo (Tabla No 1). Fue nítida la diferencia, tanto en tamaño como en aspecto de los órganos, con las intrapulmonares, resaltando el menor desarrollo. En la Tabla $N^{\circ} 2$ se aprecia, con nitidez, las diferencias.

Las glándulas vitelógenas fueron muy escasas aún a los 180 días; el útero, poco desarrollado, carecía, generalmente, de huevos y, cuando éstos aparecían, su aspecto era francamente anormal, con envolturas muy delgadas y forma irregular.

El ovario y los testiculos presentan lobulaciones cortas y delgadas que difieren radicalmente de los órganos de formas intrapulmonares.

La glándula de Mehlis estuvo representada por un esbozo leve recién a los 6 meses (Figs. 26 y 27).

Se ha comentado que P. westermani, en inoculaciones de ejemplares únicos no forma quiste parasitario ni alcanza madurez sexual (Yokogawa y cols., 1960). En nuestras observaciones siempre se usó más de 10 metacercarias, por tanto, la situación en este aspecto es diferente, aunque hay coincidencia en que las formas que no estuvieron en quistes no lo- 
graron madurez sexual, lo que no ocurre con P. miyazakii que llega a la madurez sexual aún tratándose de individuos aislados y extrapulmonares.

Al comenzar la discusión hicimos un comentario acerca del destino final de las formas extrapulmonares en animales inoculados en varias metacercarias, quedando por dilucidar si mueren o finalmente ingresan al pulmón y adquieren allí madurez sexual; pues, la totalidad de los parásitos intrapulmonares, observados por nosotros, presentaban desarrollo completo de órganos, aunque las dimensiones externas fueran diferentes.

\section{AGRADECIMIENTOS}

Expresamos nuestro mós vivo agradecimiento a las siguientes entidades $y$ personas:

Al Instituto Hipólito Unanue, que ha financiado gran parte de los gastos del presente trabajo, mediante convenio especial.

Al Sr. Director de la III Región de la Reforma Agraria, Ing" Guillermo Valdivia Rivera, quien nos facilitó movilidad para algunos viajes a las zonas endémicas.

Al Sr. Segundo Ortiz Marin, por su inestimable colaboración técnica en la ejecución de este trabajo.

Al Sr. Profesor Wilton Saldaña Sevilla, por su cooperación en el trabajo fotográfico.

Al Sr. Humberto Dalla Porta, propietario del Fundo "Tabacal", que nos brindó su generosa hospitalidad en reiteradas oportunidades.

\section{REFERENCIAS BIBLIOGRAFICAS}

AMEEL, D. J. - 1934. Paragonimus, its life history distribution in North America and its taxonomy (Trematoda: Troglotrematidae). An. Jour. Hyg. 19:279-317,

ARCE, J. - 1915. La Paragonimiasis en el Perú. La Crónica Médica. 32:249-254.
BARTON, A. L. - 1910. Un coso de distomotosis pulmonar contraída en el Perú. La Crónica Médica. 27:142-144.

CORVETTO, A. - 1921. Paragonimuiasis pulmonar. Lo Crónica Médica. 32:246-252.

CUBA, C, - 1970. Porogonimiosis: Areas endémicas determinadas en el Perú hasta la actualidad. Libro de Conferencios y Mesas redondas del III Congreso Peruano de Microbiologia y Parasitología, Trujillo. 149-154.

CUBA, C., IBANEZZ, N., FERNANDEZ, E. Y MIRANDA, H. - 1974. Paragonimus y Paraganimiasis en el Norte Peruano. Infección natu$\mathrm{ral}$ de Pseudothelphusa chilensis por metocercarias de Paragonimus Braun, 1899. (En prensa).

GRADOS, O, CUBA, C. Y MAZABEL, C. - 1967. Paragonimiasis en el Perú. Determinación de algunos áreos endémicas. Resúmenes del IV Congreso Latinoamericano de Microbiologia. 184.

GRADOS, O., CUBA, C., MAZABEL, C. y MORALES, N. - 1972. Epidemiología de la Poragonimiasis en el Perú. Arch. Peruanos Pat. clin. 26:34-36.

HASHIGUCHI, Y., TAKEI, T, and MIYAZAKI, I. - 1969. Studies on a single worm infection of albino rots with P. ohirai Miyazoki, 1939. Jap. J. Parasit. 18:612-617.

IBANEEZ, N. y MIRANDA, H - 1967. Paragonimiasis. Hallazgo de formas adultas del género Paragonimus Braun, 1899, en goto, Felis domesticus Linneo, 1758, procedente de zona endémica de Cojamarco-Perú. Arch. Peruanos Pat. Clín. 22:25-30.

15HII, Y. - 1966. Differential morphology of Paragonimus kellicotti in North America. J. Parasit. 52:920-925.

LITTLE, M. D. - 1968. Paragonimus caliensis sp. n. and Paragonimiosis in Colombia. 1 . Parasit. 54:738-746.

MIRANDA, $H$. , HERNANDEZ, O., MONTENEGRO, H. y ALVA, F. - 1967. Paragonimiasis: Nota sobre nuevas óreas de procedencia de portadores de la enfermedad.Arch. Peruanos Pat. Clín. 21:215-222.

MIYAZAKI, I. - 1964. Notes on the metocercoria of Paragonimus kellicotti Word, 1908, in North America. (Trematoda: Troglotrematidael. Jap. J. Parasit. 5:453-457.

MIYAZAKI, I. IBAÑEZ, N. and MIRANDA, $H$. - 1971. Studies on the metacercoria of Paragonimus peruvianus. Jap. J. Parasit. 20 : $425-430$.

MIYAZAKI, I. and GRADOS, 0. - 1972. The second species of the lung fluke in Perú, Paragonimus caliensis Little, 1968. Jap. J. Pa:asit, 21:275-279. 
MIYAZAKI, 1. - 1972. Occurrence of the lung fluke, Paregonimus peruvianus in Panama. J. Parasit. 58:841-842.

MIYAZAK1, 1. - 1972. Lung flukes in Westem Hemisphere. O. T. C. A. Shukosho Press, Fukuoka, Jopan.

MORALES; M. - 1963. Paragonimiasis pulmonar en el Perú. Presentoción de cinco casos. Rev. Med. Cir. (Trujillo-Perú), 1:26-40.

YOKOGAWA, M., YOSHIMURA, H. and OSHIMA T. - 1960. Studies on the experimental infection of dogs with a single metocercaria of Paragonimus westermani. Keseytsugaku Zassi, 9:636-640.
YOKOGAWA, M., YOSHIMURA, H. and TSUJI, M. - 1961. Studies on experimental infection of dogs with three metacercarie of $\mathrm{Pa}$ ragonimus westermani (Kerbert, 1878) Braun, 1899. Keseytsugaku Zassi, 10:6-13.

YOKOGAWA, M. - 1965. Paragonimus and Pagonimiasis. In "Advances in Parasitology". Acad. Press. London. Ben Dawes Ed. 36:99. 153.

YOKOGAWA, M. - 1971. Report onn a field visit to Ecuador and Peru. 1-15 August, 1971. Texto mimeografiado. 18 pógs.

YOSHIDA, T. - 1970. Studies on experimental infection with Paragonimus miyarakii to small loboratory animals. Jap. J. Parasit. 19:76-91. 
TABLA 1

INDICE DE RECUPERACION DE FORMAS DE PARAGONIMUS PERUAVIANUS OBTENIDO EN 37 GATOS DOMESTICOS FELIS CATI L. INOCULADOS CON METACERCARIAS DEL TREMATODO.

N. Ibáñex, H. Miranda, E. Fernándex y C. Cuba - Dpło. Microbiología y Parasitalogía U.N.T.

\begin{tabular}{|c|c|c|c|c|c|c|}
\hline $\begin{array}{l}\text { Gato } \\
\text { we }\end{array}$ & $\begin{array}{l}\text { Metacercarias } \\
\text { inocnladas } \\
\text { (MY) }\end{array}$ & $\begin{array}{l}\text { Necropsias: } \\
\text { Dias después } \\
\text { 1noculación }\end{array}$ & $\begin{array}{r}\text { Formas } \\
\text { Extra }\end{array}$ & $\begin{array}{l}\text { radas (No) } \\
\text { Intrapulm. }\end{array}$ & $\begin{array}{l}\text { Total de } \\
\text { Formas } \\
\text { recuperadas }\end{array}$ & $\begin{array}{c}\text { Porcentajo } \\
\text { de } \\
\text { recuperacion }\end{array}$ \\
\hline 1 & 10 & 15 & 4 & 0 & 4 & 40.0 \\
\hline 2 & 10 & 30 & 4 & 5 & 9 & 90.0 \\
\hline 3 & 20 & 30 & 1 & 6 & 7 & 35.0 \\
\hline 4 & 20 & 34 & 2 & 0 & 2 & 10.0 \\
\hline 5 & 20 & 35 & 3 & 9 & 12 & 60.0 \\
\hline 6 & 20 & 35 & 4 & 6 & 10 & 50.0 \\
\hline 7 & 20 & 37 & 1 & 15 & 16 & 80.0 \\
\hline 8 & 20 & 39 & 2 & 9 & 11 & 55.0 \\
\hline 9 & 20 & 41 & 1 & 9 & 10 & 50.0 \\
\hline 10 & 50 & 45 & 10 & 13 & 23 & 46.0 \\
\hline 11 & 10 & 60 & 0 & 0 & 9 & 90.0 \\
\hline 12 & 10 & 60 & 2 & 0 & 2 & 20.0 \\
\hline 13 & 20 & 60 & 0 & 12 & 12 & 60.0 \\
\hline 14 & 20 & 60 & 0 & 13 & 13 & 65.0 \\
\hline 15 & 20 & 60 & 0 & 15 & 15 & 75.0 \\
\hline 16 & 40 & 60 & 6 & 28 & 34 & 85.0 \\
\hline 17 & 20 & 75 & 0 & 16 & 16 & 80.0 \\
\hline 18 & 15 & 90 & 0 & 8 & 8 & 53.3 \\
\hline 19 & 20 & 90 & 0 & 15 & 15 & 75.0 \\
\hline 20 & 20 & 90 & 2 & 17 & 19 & 95.0 \\
\hline 21 & 10 & 105 & 1 & 8 & 9 & 90.0 \\
\hline 22 & 5 & 120 & 0 & 4 & 5 & 100.0 \\
\hline 23 & 10 & 120 & 0 & 6 & 6 & 60.0 \\
\hline 24 & 20 & 120 & 0 & 10 & 10 & 50.0 \\
\hline 25 & 40 & 120 & 0 & 26 & 26 & 65.0 \\
\hline 26 & 5 & 150 & 1 & 0 & 1 & 20.0 \\
\hline 27 & 10 & 150 & 0 & 3 & 3 & 30.0 \\
\hline 28 & 20 & 150 & 0 & 4 & 4 & 20.0 \\
\hline 29 & 5 & 180 & 1 & 3 & 4 & 80.0 \\
\hline 30 & 10 & 180 & 2 & 4 & 6 & 60.0 \\
\hline 31 & 20 & 210 & 0 & 16 & 16 & 80.0 \\
\hline 32 & 20 & 210 & 0 & 19 & 19 & 95.0 \\
\hline 33 & 20 & 240 & 0 & 6 & 6 & 30.0 \\
\hline 34 & 20 & 300 & 0 & 16 & 16 & 80.0 \\
\hline 35 & 100 & 360 & 0 & 37 & 37 & 37.0 \\
\hline 36 & 20 & 420 & 0 & 4 & 4 & 20.0 \\
\hline 37 & 20 & 540 & 0 & 9 & 9 & 45.0 \\
\hline TOTAL & 760 & & 48 & 380 & 428 & 56.31 \\
\hline
\end{tabular}


TABLA 2

PROGRESION DEL DESARROLLO DE P. PERUVIANUS EN GATO DOMESTICO FELIS CATI L.

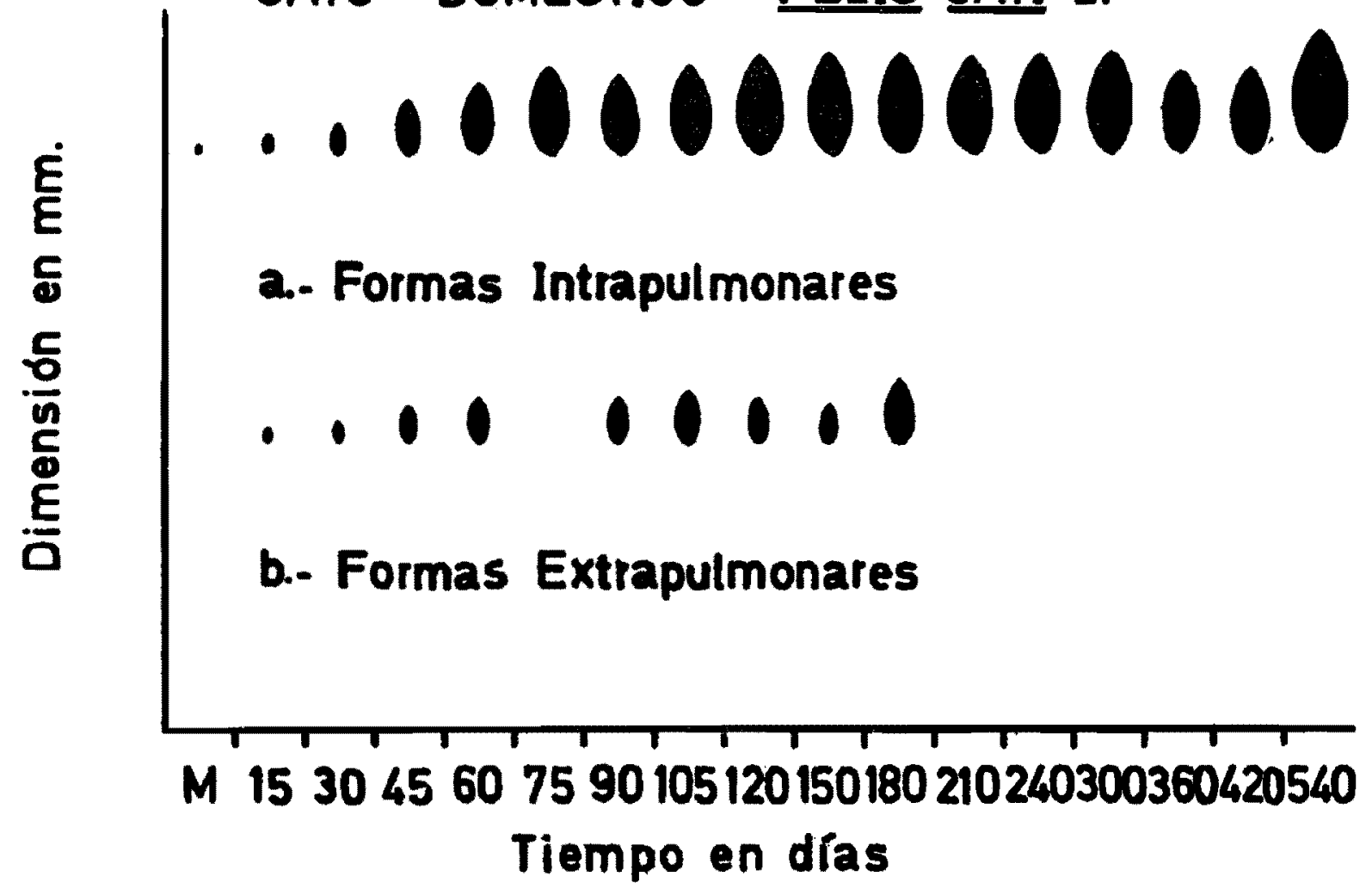

M. Ibâhez, H. Miranda, E. Fernández y C.Cuba

Dpto. Microbiologia y Parasitología U.N.T. 
TABLA No. 3

PARAGONIMUS PERUVIANUS

Dimensiones de las metacercarias de Paragonimus peruvianus de tamaño promedio N. Ibáñex, H. Miranda, E. Fernández y C. Cuba.

\begin{tabular}{|c|c|c|}
\hline 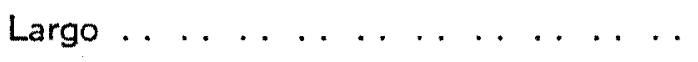 & 1.398 & 1.252 \\
\hline Ancho $\ldots \ldots \ldots \ldots \ldots$ & 0.605 & 0.699 \\
\hline & 0.093 & 0.120 \\
\hline Ventosa Oral & 0.106 & 0.157 \\
\hline & 0.244 & 0.256 \\
\hline Acetóbulo . . . . . . & 0.233 & 0.233 \\
\hline Relación Ventosa Oral - Acetábulo ... . & $1: 2.04$ & $1: 1.76$ \\
\hline & 0.093 & 0.093 \\
\hline 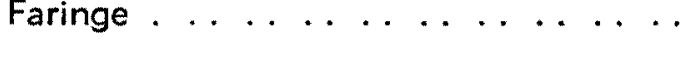 & 0.069 & 0.069 \\
\hline & 0.052 & 0.052 \\
\hline Esófago $\ldots \ldots \ldots c c c c c c c$ & 0.042 & 0.042 \\
\hline Grosor de la Cutícula . . . . . . . & 0.004 & 0.004 \\
\hline \multirow{2}{*}{ Células genitales masculinas } & 0.031 & 0.031 \\
\hline & 0.021 & 0.021 \\
\hline Dist. Ext. Ant. centro de Acetábulo . . & 0.699 & 0.639 \\
\hline
\end{tabular}


TABLA No, 4

Dimensiones de los órganos internos de las formas intrapulmonares de Paragonimus peruvianus

N. Ibáñez, H. Miranda, E. Fernández y C. Cubo.

\begin{tabular}{|c|c|c|c|c|c|c|c|c|}
\hline & $\begin{array}{c}\text { "a" } 15 \\
\text { días }\end{array}$ & $\begin{array}{c}\text { "b" } 15 \\
\text { dies }\end{array}$ & $\begin{array}{c}\text { "a' } 30 \\
\text { días }\end{array}$ & $\begin{array}{c}\text { "b" } 30 \\
\text { dias }\end{array}$ & $\begin{array}{c}\text { "a" } 45 \\
\text { dias }\end{array}$ & $\begin{array}{c}\text { "b" } 45 \\
\text { dias }\end{array}$ & $\begin{array}{c}\text { "a" } 60 \\
\text { dias }\end{array}$ & $\begin{array}{c}\text { "b" } 60 \\
\text { días }\end{array}$ \\
\hline Largo . . . . . . . . . . & 2.372 & 2.665 & 4.511 & 4.485 & 7.605 & 7.410 & 9.035 & 9.555 \\
\hline Ancho , . . . . & 1.332 & 1.274 & 2.210 & 2.210 & 3.770 & 3.575 & 4.680 & 4.940 \\
\hline & 0.279 & 0.246 & 0.326 & 0.419 & 0.520 & 0.455 & 0.520 & 0.520 \\
\hline Ventosa Oral ..... & 0.302 & 0.326 & 0.614 & 0.516 & 0.624 & 0.715 & 0.715 & 0.585 \\
\hline & 0.349 & 0.372 & 0.512 & 0.489 & 0.520 & 0.715 & 0.715 & 0.585 \\
\hline Acetábulo . . . . . & 0.362 & 0.359 & 0.489 & 0.521 & 0.650 & 0.585 & 0.689 & 0.650 \\
\hline Relac. V. Oral - Acet. . . & $1: 1.22$ & $1: 1.02$ & $1: 1.06$ & $1: 1.08$ & $1: 1.02$ & $1: 1.1$ & $1: 1.1$ & $1: 1.1$ \\
\hline & 0.186 & 0.233 & 0.233 & 0.242 & 0.325 & no & 0.390 & 0.390 \\
\hline Foringe & 0.162 & 0.209 & 0.246 & 0.269 & 0.390 & visto & 0.442 & 0.390 \\
\hline & 0.093 & 0.139 & 0.093 & 0.093 & no & no & 0.325 & 0.260 \\
\hline Esófogo $\ldots \ldots$ & 0.093 & 0.069 & 0.093 & 0.106 & visto & visto & 0.260 & 0.260 \\
\hline \multicolumn{9}{|l|}{ Dist. Ext. Ant. Borde Inf. } \\
\hline Acetábulo $\ldots \ldots \ldots$ & 1.254 & 1.495 & 2.080 & 2.249 & 3.315 & 3.549 & 3.900 & 4.654 \\
\hline & 0.186 & 0.139 & 1.066 & 1.040 & 2.015 & 2.340 & 2.626 & 3.185 \\
\hline Testiculo Derecho & 0.093 & 0.129 & 0.390 & 0.858 & 1.040 & 0.910 & 1.183 & 1.885 \\
\hline & 0.162 & 0.186 & 0.949 & 1.040 & 1.625 & 1.430 & 1.703 & 2.340 \\
\hline Testículo Izquierdo . . & 0.139 & 0.139 & 0.650 & 0.585 & 1.040 & 1.092 & 1.170 & 1.560 \\
\hline & 0.233 & 0.233 & 0.520 & 0.650 & 1.105 & 0.975 & 1.235 & 1.300 \\
\hline Ovario ..... & 0.233 & 0.279 & 0.442 & 0.455 & 0.832 & 0.936 & 1.313 & 1.105 \\
\hline &.-- & $-\cdot-$ &.-- &.-- & 0.910 & 0.780 & 0.975 & 1.040 \\
\hline Glóndulo de Mehlis . . &.-- & -- &.-- &.-- & 0.585 & 0.455 & 0.780 & 0.845 \\
\hline & 0.102 & 0.162 & 0.520 & 0.910 & ㅇ 2.119 & 1.625 & 2.860 & 2.236 \\
\hline Esbozo de Utero ... .. & 0.102 & 0.116 & 0.455 & 0.520 & $\stackrel{\$}{\leftrightarrows} 1.495$ & 1.040 & 2.714 & 1.690 \\
\hline Hetaras &.-- &.-- &.- &.-- & -0.084 & 0.086 & 0.084 & 0.087 \\
\hline Huevos $\ldots$ &.-- &.-- &.-- &.-- & 0.042 & 0.033 & 0.061 & 0.040 \\
\hline
\end{tabular}


TABLA No. 4-A

Dimensiones de los órganos internos de las formas intrapulmonares de Paragonimus peruvianus

N. Ibáñez, H. Miranda, E. Fernández y C. Cubo.

\begin{tabular}{|c|c|c|c|c|c|c|c|c|}
\hline & $\begin{array}{l}\text { "a" } 75 \\
\text { díos }\end{array}$ & $\begin{array}{l}\text { "b" } 75 \\
\text { dias }\end{array}$ & $\begin{array}{l}\text { "as" } 90 \\
\text { dias }\end{array}$ & $\begin{array}{l}\text { "b" } 90 \\
\text { dias }\end{array}$ & $\begin{array}{c}\text { "o" } 105 \\
\text { dies }\end{array}$ & $\begin{array}{c}\text { "b" } 105 \\
\text { dias }\end{array}$ & $\begin{array}{l}\text { "a" } 120 \\
\text { dias }\end{array}$ & "b" 120 \\
\hline Lorgo . . . . . . . . . . & 12.220 & 11.895 & 10.400 & 12.350 & 11.050 & 12.350 & 13.260 & 13.650 \\
\hline Ancho $\ldots \ldots \ldots$ & 5.200 & 5.148 & 6.500 & 7.020 & 5.915 & 5.915 & 6.760 & 6.110 \\
\hline \multirow{3}{*}{ Ventosa Oral .. $\ldots$} & 0.559 & 0.520 & 0.650 & 0.686 & 0.585 & 0.715 & 0.715 & 0.585 \\
\hline & 0.780 & 0.780 & 0.884 & 0.910 & 0.780 & 0.806 & 0.936 & 0.715 \\
\hline & 0.650 & 0.650 & 0.747 & 0.676 & 0.650 & 0.754 & 0.802 & 0.702 \\
\hline Acetóbulo . & 0.715 & 0.728 & 0.845 & 0.741 & 0.715 & 0.715 & 0.802 & 0.780 \\
\hline \multirow{2}{*}{ Relac. V. Oral - Acet. . } & $1: 1.01$ & $1: 1.05$ & $1: 1.02$ & $1: 0.88$ & $1: 1$ & $1: 0.95$ & $1: 0.97$ & $1: 1.14$ \\
\hline & 0.429 & 0.351 & 0.390 & 0.390 & 0.390 & 0.390 & -.- &.-- \\
\hline \multirow{2}{*}{ Foringe } & 0.390 & 0.429 & 0.429 & 0.416 & 0.520 & 0.455 &.-- &.-- \\
\hline & 0.390 & 0.390 & 0.325 & 0.364 & 0.260 & 0.325 & -.- &.-- \\
\hline Esófago $\cdot \ldots$ & 0.429 & 0.390 & 0.286 & 0.390 & 0.390 & 0.390 & -. - &.-- \\
\hline \multicolumn{9}{|l|}{ Dist. Ext. Ant. Borde Inf. } \\
\hline Acetóbulo $\ldots \ldots$ & 5.395 & 5.135 & 4.745 & 5.330 & 4.899 & 5.785 & 6.240 & 5.980 \\
\hline \multirow{3}{*}{ Testículo Derecho } & 2.990 & 2.990 & 3.900 & 4.134 & 2.106 & 2.665 & 2.730 & 4.208 \\
\hline & 1.300 & 1.170 & 2.015 & 1.846 & 1.625 & 1.690 & 2.145 & 2.004 \\
\hline & 1.885 & 2.340 & 2.600 & 2.639 & 2.080 & 2.080 & 2.340 & 3.607 \\
\hline \multirow{2}{*}{ Testiculo Izquierdo. } & 1.105 & 1.170 & 1.664 & 1.300 & 1.235 & 1.560 & 1.430 & 2.004 \\
\hline & 1.300 & 1.300 & 1.716 & 2.080 & 1.560 & 1.547 & 1.560 & 1.803 \\
\hline \multirow[t]{2}{*}{ Ovario $\ldots \begin{array}{llll} & \ldots & \ldots & \ldots\end{array}$} & 1.300 & 1.300 & 1.755 & 1.820 & 1.326 & 1.755 & 1.755 & 1.903 \\
\hline & 1.300 & 1.170 & 1.365 & 1.235 & 1.300 & 1.560 & 1.625 & 1.803 \\
\hline \multirow{2}{*}{ Glándula de Mehlis } & 0.845 & 0.975 & 1.040 & 1.170 & 1.040 & 1.170 & 1.105 & 2.004 \\
\hline & 2.678 & 2.730 & 4.056 & 3.575 & 2.990 & 3.055 & 3.198 & 2.108 \\
\hline \multirow{2}{*}{ Utero } & 1.950 & 1.950 & 2.730 & 2.600 & 2.730 & 2.470 & 2.340 & 3.406 \\
\hline & 0.073 & 0.073 & 0.080 & 0.073 & 0.079 & 0.078 & 0.080 & 0.093 \\
\hline Huevos & 0.038 & 0.039 & 0.048 & 0.052 & 0.052 & 0.048 & 0.048 & 0.046 \\
\hline
\end{tabular}


TABLA No. 4-B

Dimensiones de los órganos internos de las formas intrapulmonares de Paragonimus peruvianus

N. Ibáñez, H. Miranda, E. Fernández y C. Cuba.

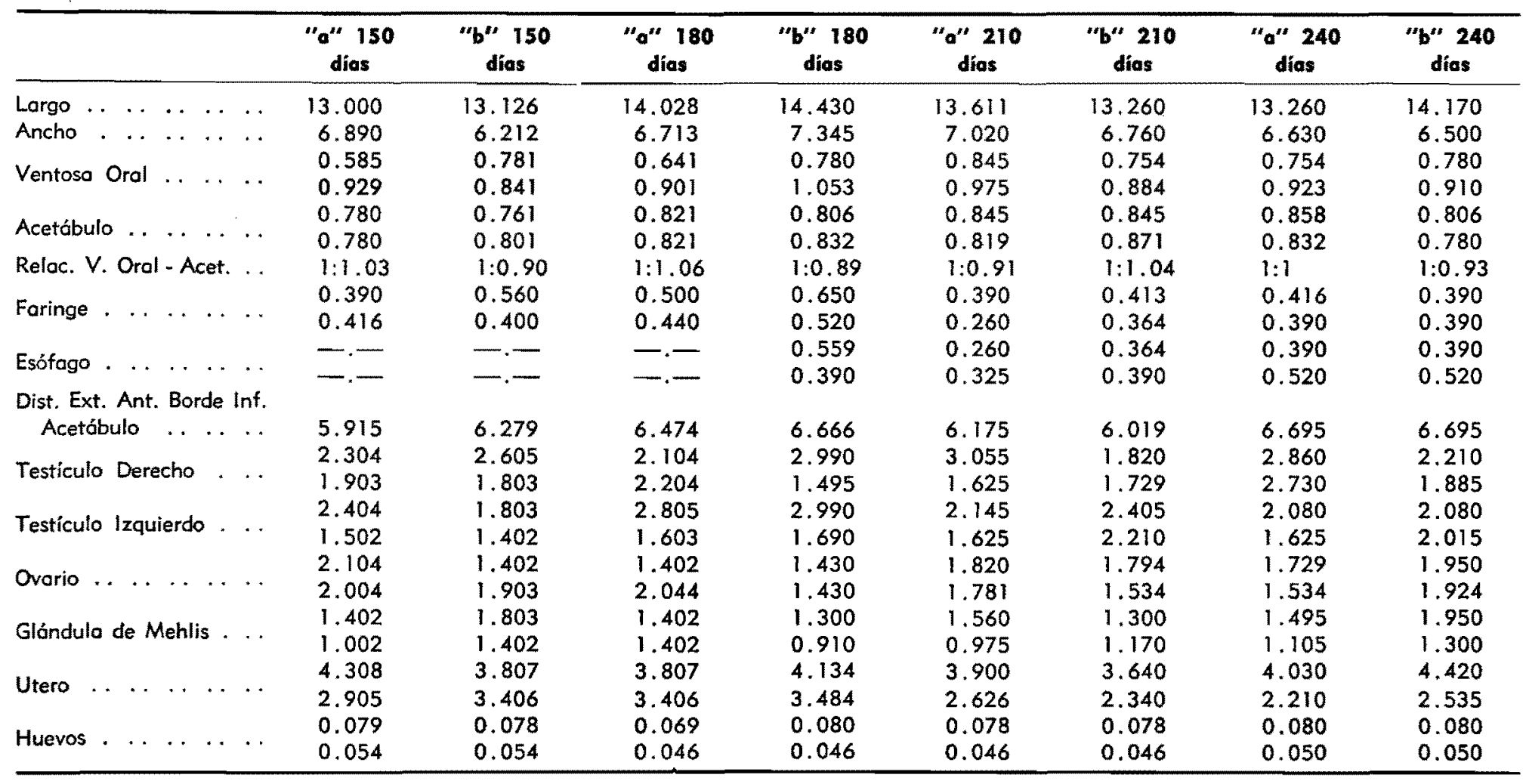


TABLA No. 4-C

Dimensiones de los órganos internos de las formas intrapulmonares de Paragonimus peruvianus

N. Ibáñez, H. Miranda, E. Femóndez y C. Cuba.

\begin{tabular}{|c|c|c|c|c|c|c|c|c|}
\hline & $\begin{array}{l}\text { "a" } 300 \\
\text { días }\end{array}$ & $\begin{array}{l}\text { "b" } 300 \\
\text { días }\end{array}$ & $\begin{array}{l}\text { "a" } 365 \\
\text { días }\end{array}$ & $\begin{array}{l}\text { "b" } 365 \\
\text { días }\end{array}$ & $\begin{array}{l}\text { "a" } 420 \\
\text { días }\end{array}$ & $\begin{array}{l}\text { "b" } 420 \\
\text { díos }\end{array}$ & $\begin{array}{l}\text { "a" } 540 \\
\text { díos }\end{array}$ & $\begin{array}{l}\text { "b" } 540 \\
\text { días }\end{array}$ \\
\hline Largo .. & 13.455 & 15.470 & 15.600 & 14.300 & 14.066 & 12.675 & 16.760 & 17.485 \\
\hline Ancho . & 6.370 & 6.734 & 6.955 & 7.280 & 6.656 & 6.240 & 8.710 & 8.125 \\
\hline \multirow{2}{*}{ Ventosa Oral $\ldots \ldots \ldots$} & 0.715 & 0.715 & 0.780 & 0.650 & 0.520 & 0.520 & 0.780 & 0.390 \\
\hline & 0.910 & 0.936 & 0.910 & 0.910 & 1.027 & 0.650 & 1.183 & 0.585 \\
\hline & 0.832 & 0.838 & 0.845 & 0.884 & 0.754 & 0.819 & 0.845 & 0.910 \\
\hline Acetábulo ... & 0.897 & 0.890 & 0.819 & 0.819 & 0.780 & 0.780 & 0.741 & 0.910 \\
\hline \multirow[t]{2}{*}{ Relac. V. Oral - Acet. . . } & $1: 1.06$ & $1: 1.04$ & $1: 0.98$ & $1: 1.08$ & $1: 0.99$ & $1: 1.36$ & -. - &.-- \\
\hline & 0.520 & 0.520 & 0.445 & 0.403 & 0.416 & 0.455 & 0.455 &.-- \\
\hline \multirow{2}{*}{ Foringe } & 0.390 & 0.390 & 0.390 & 0.416 & 0.390 & 0.455 & 0.520 & -. - \\
\hline & 0.715 & 0.845 & 0.780 & 0.780 & 0.520 & 0.780 &.-- &.-- \\
\hline$\cdots \cdots$ & 0.169 & 0.325 & 0.260 & 0.260 & 0.260 & 0.260 &.-- & -.- \\
\hline \multicolumn{9}{|l|}{ Dist. Ext. Ant. Borde Int. } \\
\hline \multirow{2}{*}{ Acetábulo $\ldots \ldots$} & 6.812 & 7.150 & 6.864 & 5.785 & 6.305 & 5.980 & 7.215 & 7.865 \\
\hline & 2.509 & 2.938 & 3.640 & 3.016 & 2.600 & 2.860 & 2.236 & 2.535 \\
\hline \multirow{2}{*}{ Testiculo Derecho . . } & 2.600 & 2.470 & 1.495 & 1.560 & 1.690 & 1.885 & 1.586 & 2.990 \\
\hline & 2.925 & 2.210 & 2.730 & 2.145 & 2.015 & 2.600 & 2.730 & 2.315 \\
\hline \multirow[t]{2}{*}{ Testículo Izquierdo } & 1.495 & 1.365 & 1.495 & 2.340 & 2.054 & 1.300 & 2.080 & 1.820 \\
\hline & 1.820 & 1.755 & 1.950 & 1.794 & 1.768 & 2.236 & 2.340 & 2.535 \\
\hline \multirow[t]{2}{*}{ Ovario } & 1.950 & 1.976 & 1.950 & 1.755 & 1.300 & 1.820 & 2.340 & 2.805 \\
\hline & 1.430 & 1.560 & 1.820 & 1.950 & 1.794 & 2.080 & 2.340 & 1.560 \\
\hline \multirow[t]{2}{*}{ Glándula de Mehlis } & 1.560 & 1.300 & 1.040 & 1.365 & 1.755 & 1.430 & 1.430 & 1.950 \\
\hline & 4.225 & 3.640 & 3.510 & 4.420 & 4.680 & 4.874 & 3.835 & 5.720 \\
\hline Utero & 2.626 & 2.535 & 2.860 & 4.030 & 2.470 & 2.145 & 4.095 & 4.160 \\
\hline & 0.082 & 0.082 & 0.082 & 0.082 & 0.082 & 0.078 & 0.082 & 0.082 \\
\hline Huevos & 0.052 & 0.052 & 0.052 & 0.052 & 0.046 & 0.046 & 0.055 & 0.055 \\
\hline
\end{tabular}




\section{TABLA No. 5}

Dimensiones de los órganos internos de las formas extrapulmonares de Paragonimus peruvianus

N. Ibáñez, H. Miranda, E. Fernóndez y C. Cubo.

\begin{tabular}{|c|c|c|c|c|c|c|c|c|c|c|}
\hline & $\begin{array}{l}15 \\
\text { días }\end{array}$ & $\begin{array}{l}30 \\
\text { días }\end{array}$ & $\begin{array}{l}45 \\
\text { días }\end{array}$ & $\begin{array}{l}60 \\
\text { dias }\end{array}$ & $\begin{array}{l}90 \\
\text { dias }\end{array}$ & $\begin{array}{l}105 \\
\text { dias }\end{array}$ & $\begin{array}{l}120 \\
\text { días }\end{array}$ & $\begin{array}{l}150 \\
\text { dias }\end{array}$ & $\begin{array}{l}\text { 180a } \\
\text { días }\end{array}$ & $\begin{array}{l}180 b \\
\text { dias }\end{array}$ \\
\hline Largo & 1.930 & 2.705 & 5.490 & 6.012 & 5.010 & 7.114 & 5.971 & 5.711 & 7.254 & 10.060 \\
\hline Ancho & 0.871 & 1.602 & 2.484 & 2.895 & 2.104 & 3.206 & 2.605 & 2.905 & 3.386 & 4.809 \\
\hline \multirow{3}{*}{ Ventosa Oral } & 0.125 & 0.279 & 0.468 & 0.422 & 0.455 & 0.598 & 0.494 & 0.390 & 0.533 & 0.585 \\
\hline & 0.125 & 0.302 & 0.468 & 0.585 & 0.520 & 0.650 & 0.624 & 0.585 & 0.689 & 0.845 \\
\hline & 0.297 & 0.392 & 0.404 & 0.637 & 0.585 & 0.780 & 0.689 & 0.611 & 0.715 & 0.767 \\
\hline Acetábulo & 0.297 & 0.372 & 0.494 & 0.585 & 0.585 & 0.780 & 0.715 & 0.741 & 0.721 & 0.780 \\
\hline \multirow{2}{*}{ Relac. V. Oral - Acet. } & $1: 2.3$ & $1: 1.3$ & $1: 1.05$ & $1: 1.25$ & $1: 1.20$ & $1: 1.25$ & $1: 1.25$ & $1: 1.47$ & $1: 1.17$ & $1: 1.08$ \\
\hline & 0.082 & 0.162 & 0.260 & 0.286 & 0.377 & 0.351 & 0.195 & 0.136 & 0.455 & 0.416 \\
\hline \multirow[t]{2}{*}{ Faringe } & 0.069 & 0.139 & 0.260 & 0.247 & 0.273 & 0.390 & 0.195 & 0.260 & 0.325 & 0.455 \\
\hline & & 0.093 & 0.130 & 0.156 & 0.200 & 0.200 & 0.130 & 0.156 & 0.156 & 0.390 \\
\hline Esófago $\ldots \ldots$ & 0.055 & 0.093 & 0.156 & 0.130 & 0.200 & 0.440 & 0.130 & 0.130 & 0.234 & 0.195 \\
\hline \multirow[b]{2}{*}{ Testículo Derecho } & 0.102 & 0.250 & 1.803 & 1.430 & 1.320 & 1.843 & 1.170 & 1.508 & 1.430 & 2.613 \\
\hline & 0.062 & 0.200 & 0.901 & 0.728 & 0.420 & 1.102 & 0.650 & 0.689 & 0.975 & 1.170 \\
\hline \multirow{3}{*}{ Testiculo Izquierdo } & 0.139 & 0.150 & 1.402 & 0.910 & 0.800 & 1.803 & 1.170 & 1.105 & 1.430 & 1.755 \\
\hline & 0.070 & 0.200 & 0.701 & 0.650 & 0.240 & 0.500 & 0.403 & 0.650 & 0.910 & 1.040 \\
\hline & 0.141 & 0.300 & 0.801 & 0.546 & 0.500 & 0.910 & 0.650 & 0.910 & 1.430 & 1.690 \\
\hline \multirow{2}{*}{ Ovario .. } & 0.095 & 0.220 & 0.400 & 0.585 & 0.400 & 0.819 & 0.780 & 0.715 & 0.910 & 1.144 \\
\hline & -. - & 0.400 &.- &.-- & 0.400 & - . - &.-- & 0.260 & 0.780 & 1.014 \\
\hline \multirow[t]{2}{*}{ Glándula de Mehlis } & -.. & 0.555 &.-- & -.- & 0.160 &.-- &.-- & 0.390 & 0.780 & 0.780 \\
\hline &.- &.--1 &.-- & -. - & 1.300 & 1.170 & 0.910 & 0.780 &.- &.-- \\
\hline \multirow[t]{2}{*}{ Utero } &.-- &.-- &.--- &.-- & 0.845 & 0.910 & 0.780 & 0.650 & 1.105 &.-- \\
\hline &.-- &.-- & -.- & 0.069 &.-- &.- &.-- &.-- & 0.069 & 0.073 \\
\hline Huevos &.-- &.--- &.-- & 0.046 &.-- & -.- &.-- &,-- & 0.042 & 0.042 \\
\hline
\end{tabular}



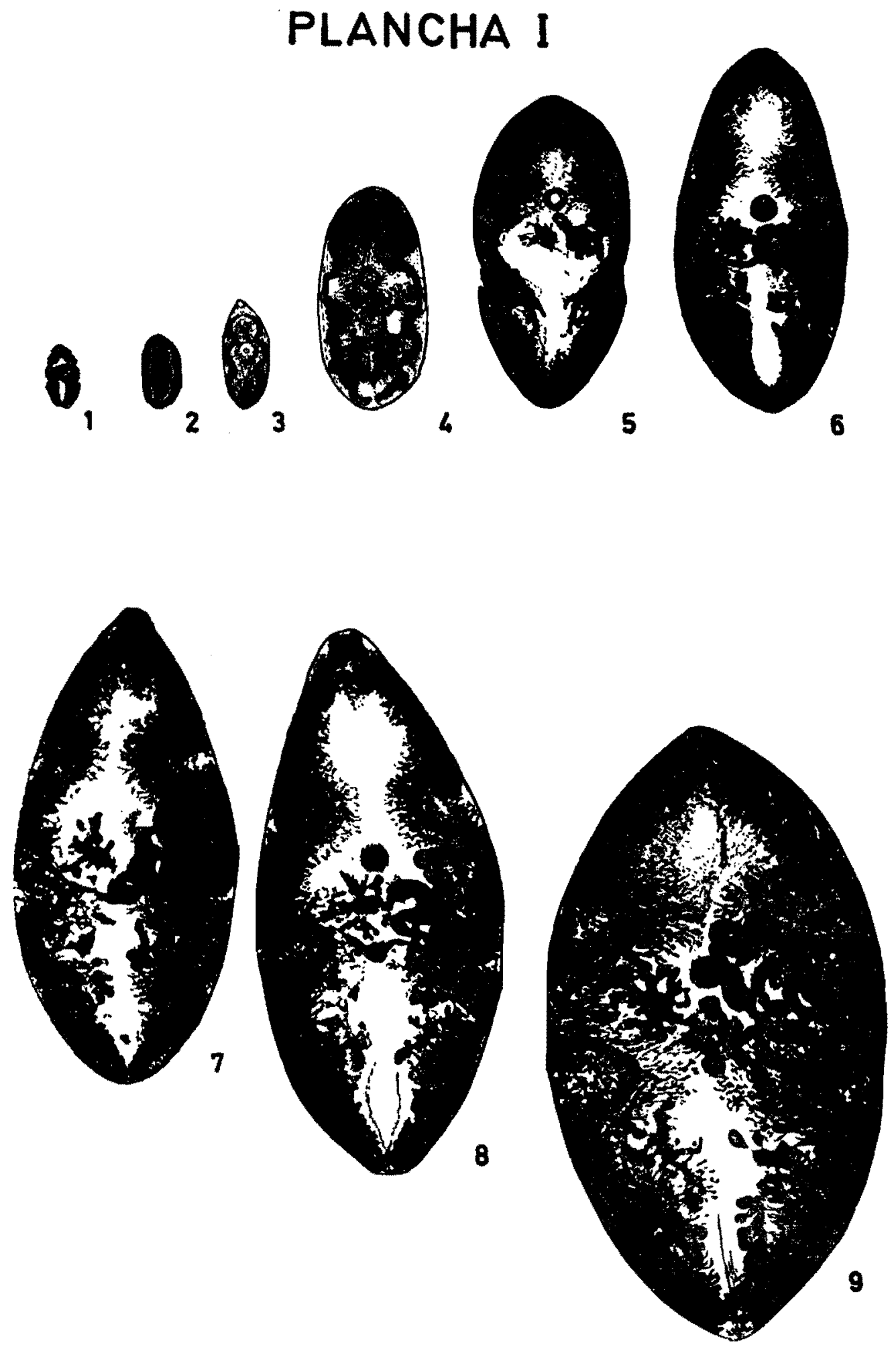

Fig. 1.-Metocercario de Paragonimus peruvianus.

Fig. 2.-Forma migratorio de 5 días.

Figs. 3 a 9.-Formos intrapulmonares de 15, 30, 37, 45, 60, 75 y 90 días.

Fotografias: Hernán Miranda $C$. 


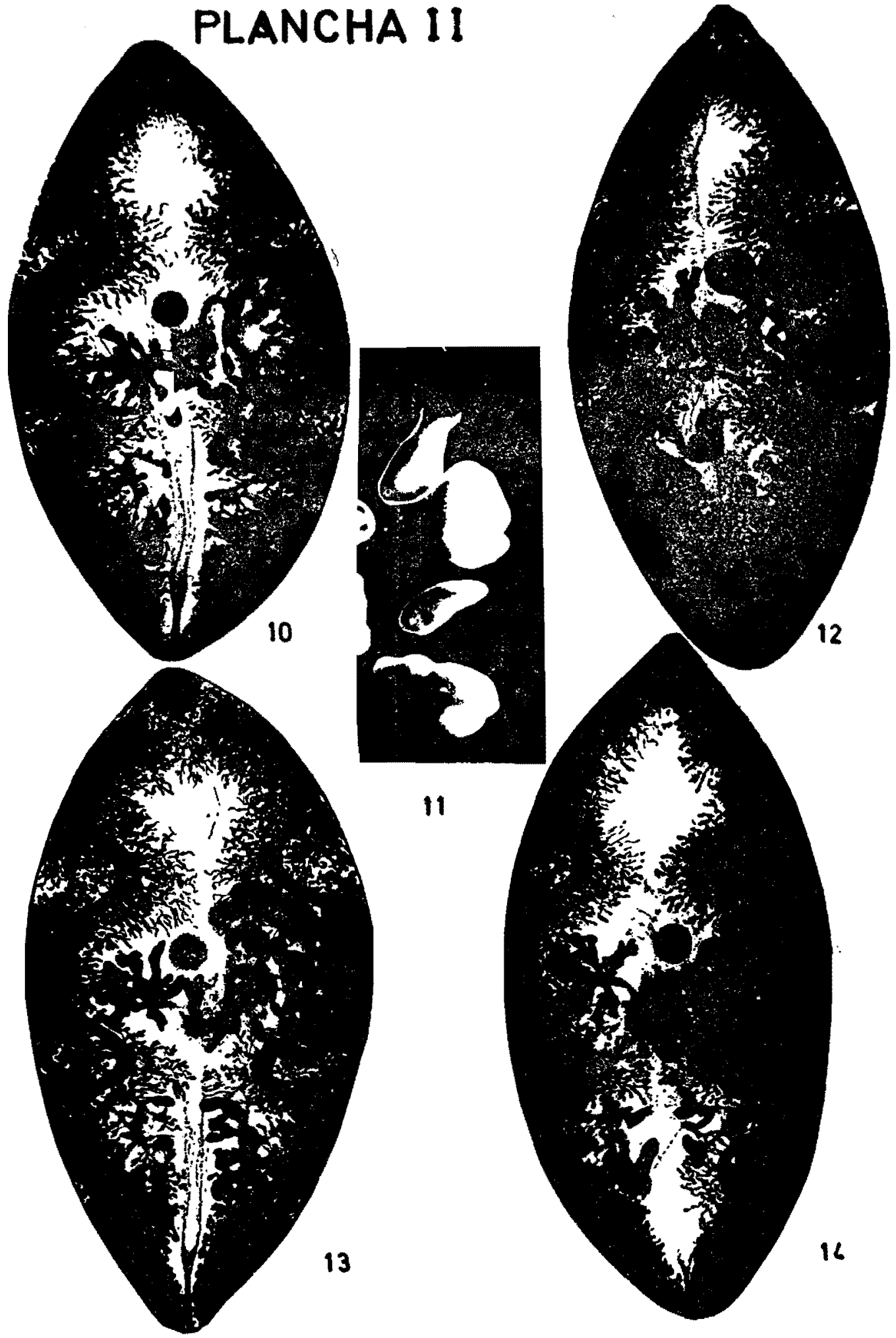

Figs. 10 y 12 a 14.-Formas intrapulmonares de 150, 180, 210 y 240 dias.

Fig. 11.-Parásitos recién extraidos, sin fijación.

Fotografías: Hernán Miranda C. 


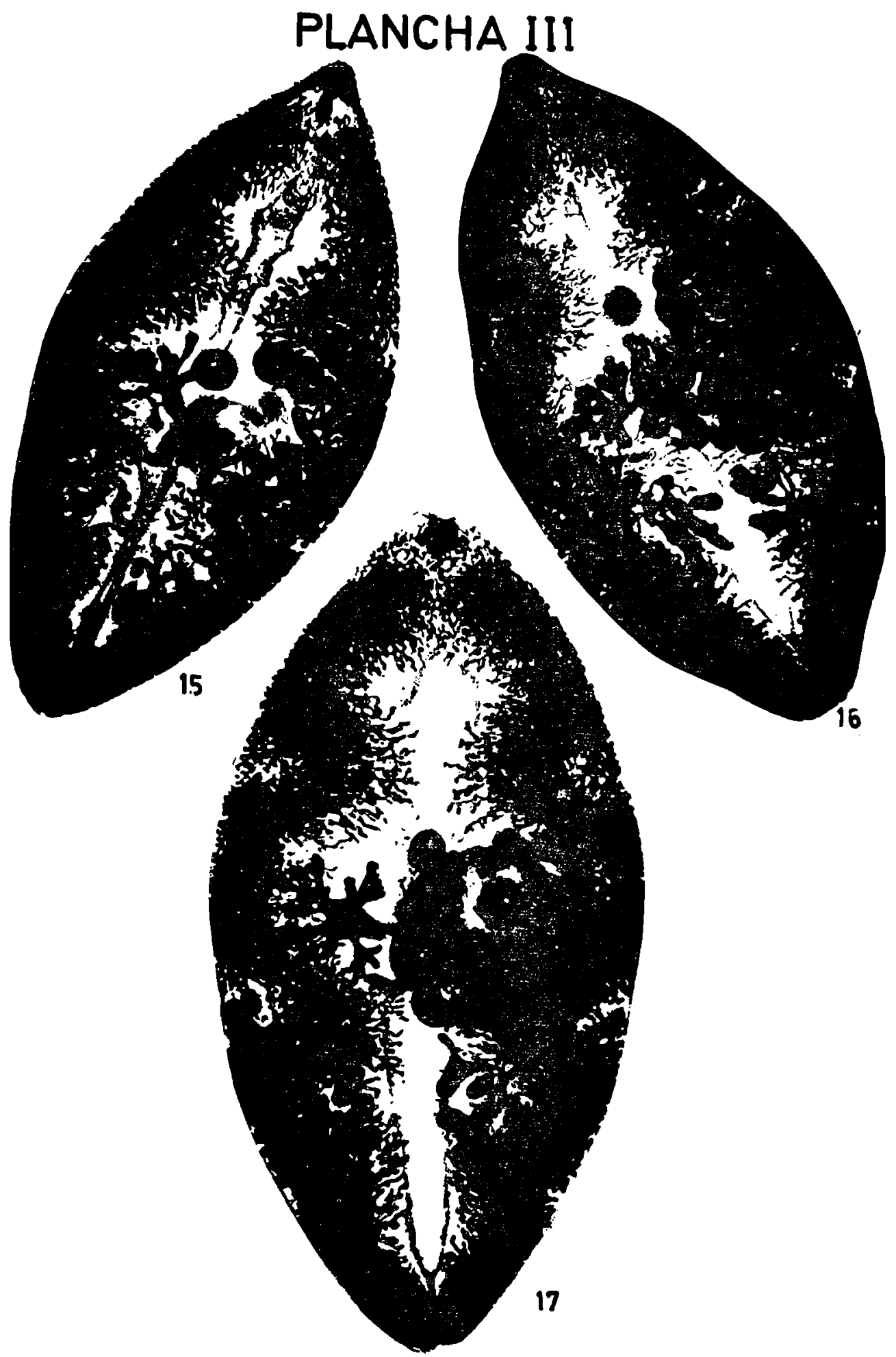

Figs. 15 a 17.-Formas intrapulmonares de 300,360 y 540 dias.

Fotografías: Hernán Miranda C. 


$$
\begin{aligned}
& 0 \\
& 00
\end{aligned}
$$


PLANCHA $V$
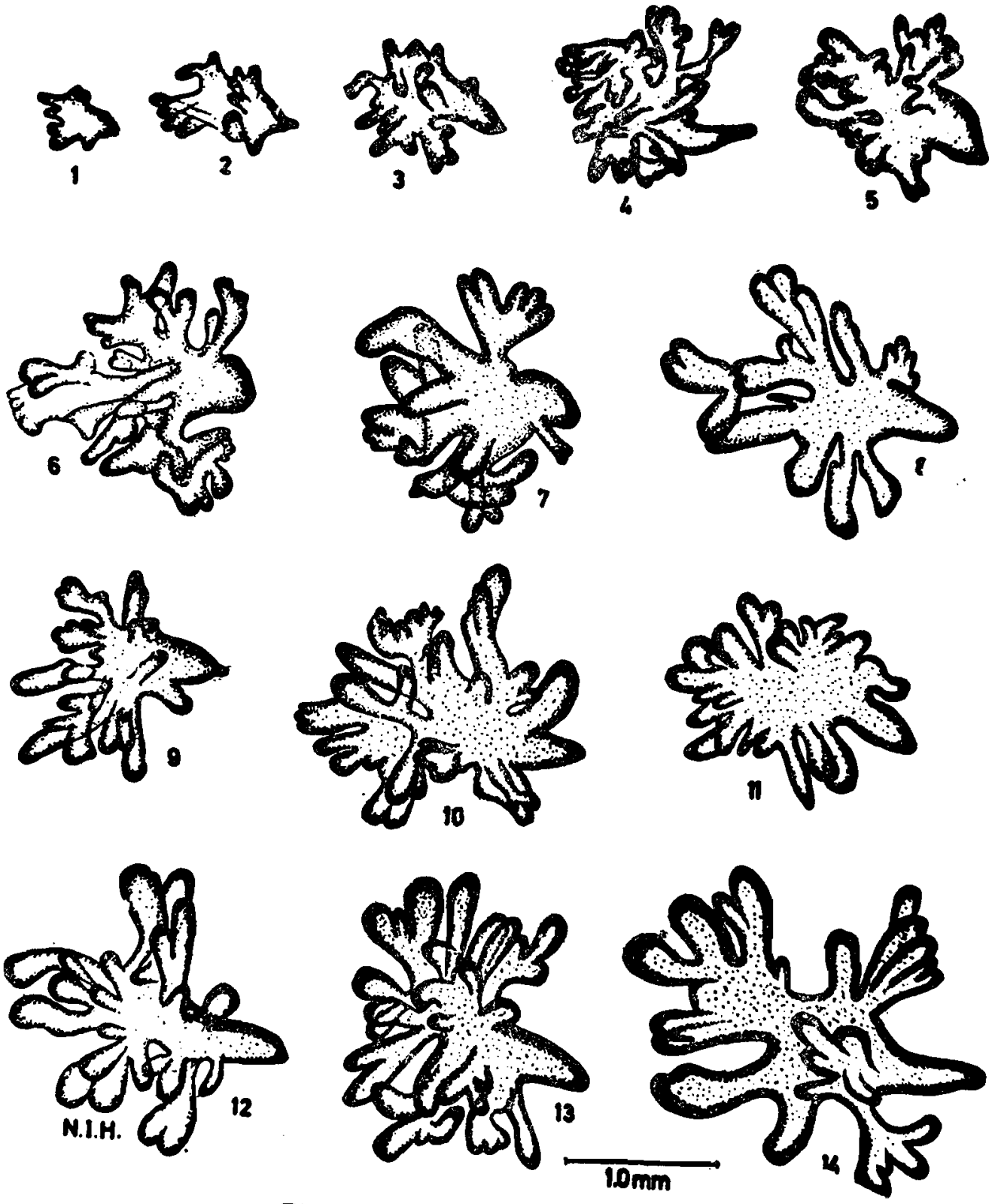

Fig.. $\quad 28$

Figs. 1 a 14.-Esquema en cámara clara de los ovarios de P. peruvianus de $30,37,45$, $60,75,90,120,150,180,210,240,300,360$ y 540 días.

Dibujos: Nicanor lbáñez $H$. 

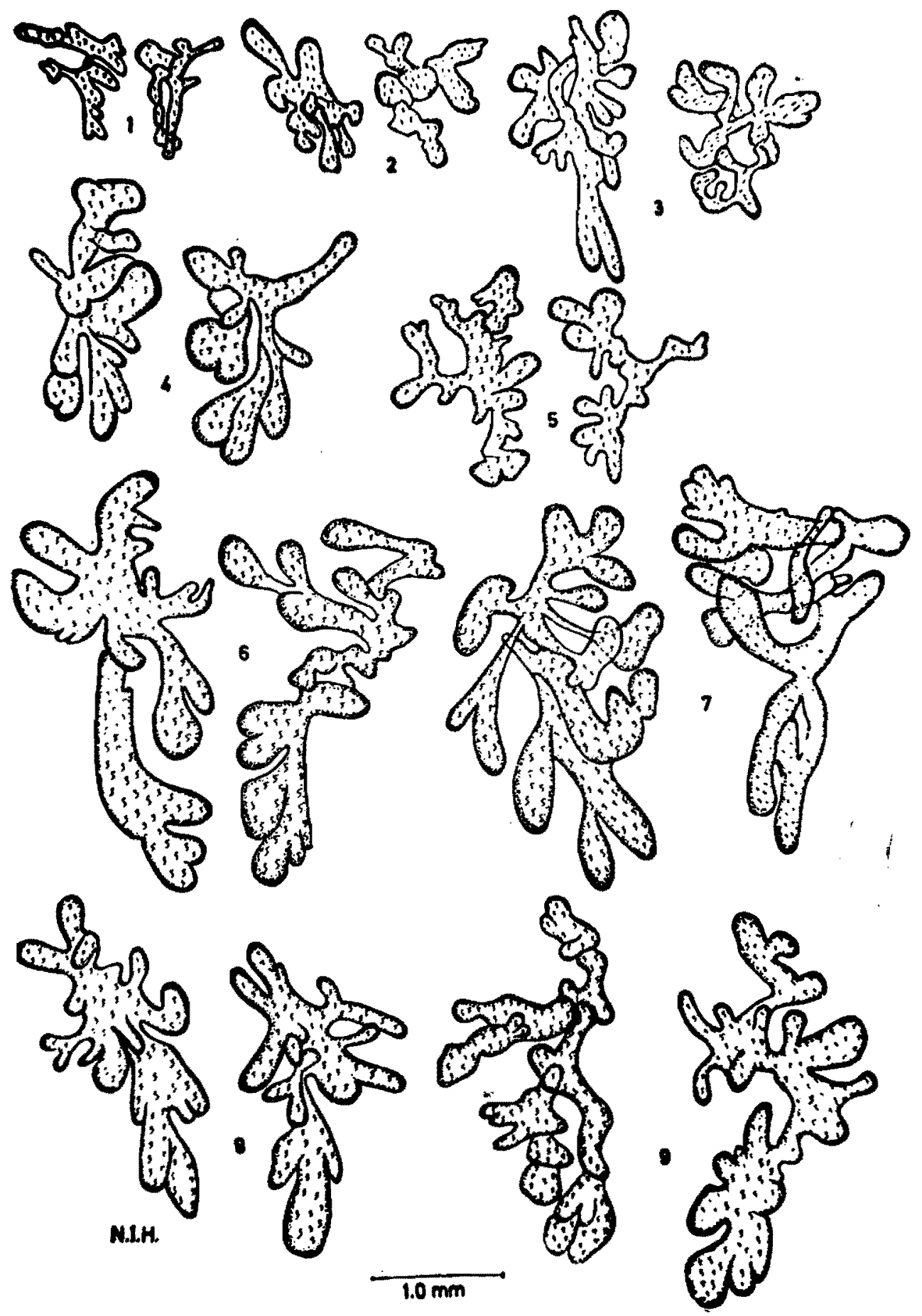

Fig. - 29

Fig. 29.-Esquema en cámara clara de los testículos de P. peruvianus de $30,37,45,60$, 75,90 y 120 días.

Dibujos: Nicanor lbáñez $H$. 


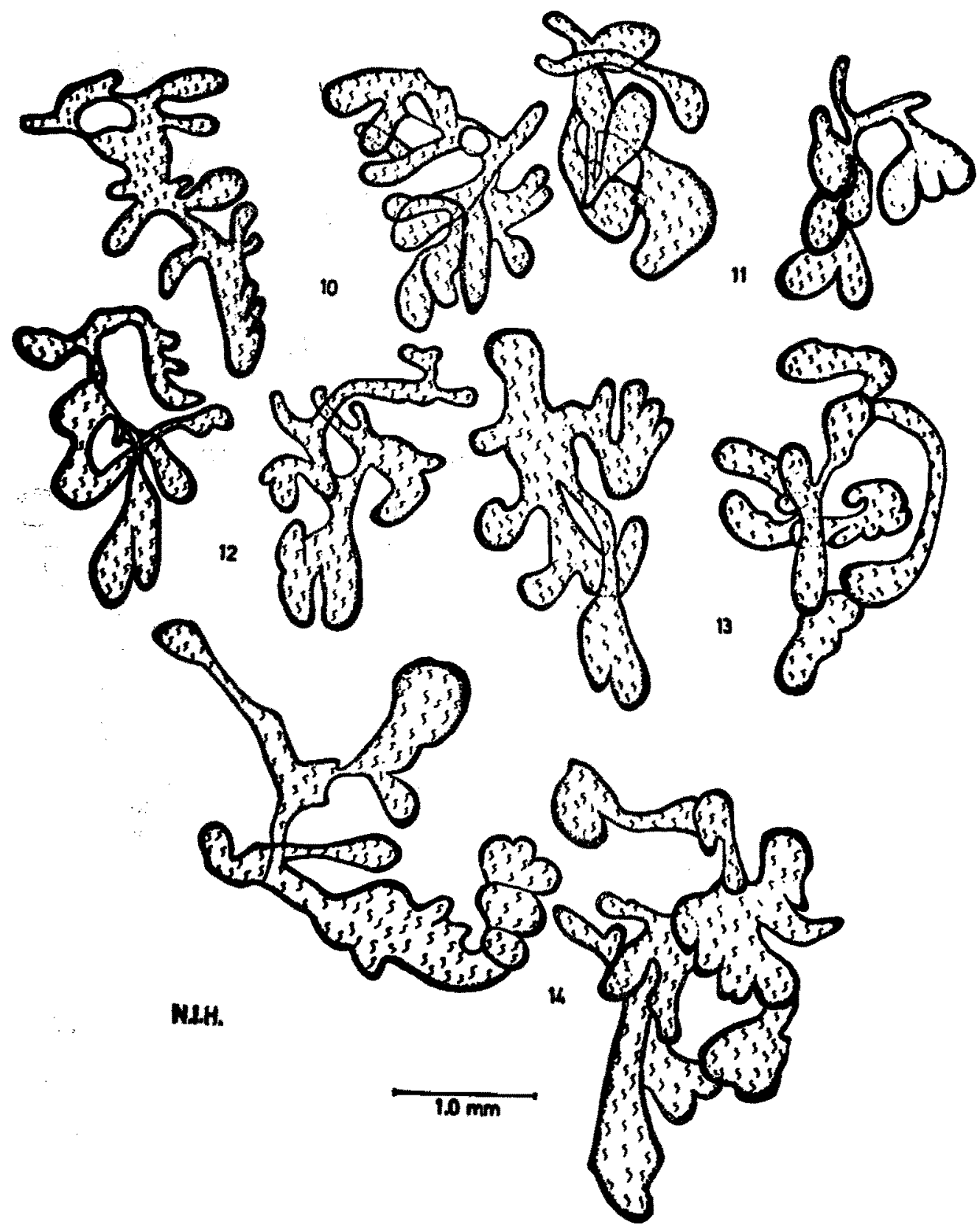

Fig. 30

Fig. 30.-Esquemo en cámara clara de los testículos de P. peruvianus de 150, 180, 210, $240,300,360$ y 540 díos.

Dibujos: Niconor Ibánez $H$. 